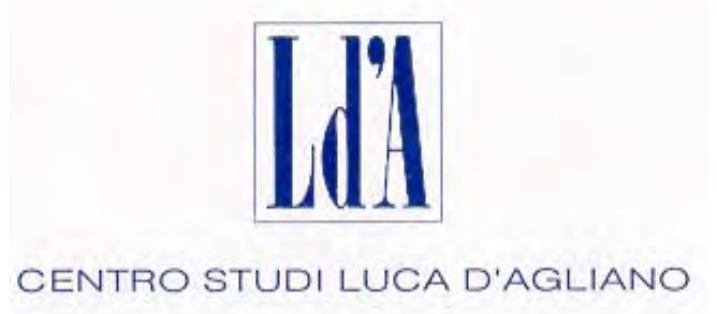

WWW.DAGLIANO.UNIMI.IT

\author{
CENTRO STUDI LUCA D'AGLIANO \\ DEVELOPMENT STUDIES WORKING PAPERS
}

N. 284

November 2009

The Evolution of Markets and the Revolution of Industry:

A Unified Theory of Growth

\author{
Klaus Desmet* \\ Stephen L. Parente**
}

* Universidad Carlos III, CEPR and Centro Studi Luca d'Agliano ** University of Illinois and CRENoS 


\title{
The Evolution of Markets and the Revolution of Industry: A Unified Theory of Growth*
}

\author{
Klaus Desmet \\ Universidad Carlos III \\ and CEPR
}

\author{
Stephen L. Parente \\ University of Illinois \\ and CRENoS
}

October 2009

\begin{abstract}
This paper puts forth a unified theory of growth that captures a number of relevant features of countries' transitions from stagnant, predominantly rural economies to vibrant, industrialized economies that have been overlooked by the literature. In our theory, increasing variety of consumer goods and increasing firm size, which are the consequence of a gradual expansion in the market, sow the seeds for process innovation and an economy's take-off. We demonstrate this mechanism in a dynamic general equilibrium model calibrated to England's long-run development, and explore how various factors affected the timing of its take-off.
\end{abstract}

JEL Classification: 014, 033, 041, N33

Keywords: Unified Growth Theory, Industrial Revolution, Innovation, Competition, Market Revolution

\footnotetext{
*We thank Oded Galor, Douglas Gollin, Berthold Herrendorf, Peter Howitt, Chad Jones, Richard Rogerson, David Weil, and Dennis Yang, as well as seminar participants at the 2008 NBER Meeting on Economies across space and time, 2008 Midwest Macro Meetings, 2008 SED Meetings, Penn State, Arizona State, Tufts University, Federal Reserve Bank of Atlanta, Federal Reserve Bank of San Francisco, Amsterdam, Università di Cagliari, CEMFI, Stockholm School of Economics, Namur, and Tinbergen Institute. Financial aid from the European Commission (EFIGE Grant 225343 and HI-POD Grant 225551), the Comunidad de Madrid (PROCIUDAD-CM), and the Spanish Ministry of Science (ECO2008-01300) is acknowledged. The usual disclaimer applies. Desmet: Department of Economics, Universidad Carlos III. E-mail: klaus.desmet@uc3m.es; Parente: Department of Economics, University of Illinois at Urbana-Champaign. E-mail: parente@illinois.edu.
} 


\section{Introduction}

In clarifying the process by which economies transition from Malthusian stagnation to modern economic growth, unified growth theory provides an ideal theoretical framework for studying the causes of the Industrial Revolution. ${ }^{1}$ However, although this literature elucidates one of history's great mysteries, it has not accounted for a number of salient features of countries' transitions from stagnant, predominantly rural economies to vibrant, industrial economies. The objective of this paper is to enhance our understanding of the causes of the Industrial Revolution by putting forth a unified growth theory consistent with a number of relevant features previously overlooked.

The main features captured in our theory are the large increase in the variety of consumer goods that preceded the Industrial Revolution, the so-called Consumer Revolution documented by Styles (2000) and Berg (2002), and the organizational shift in the workplace from the cottage industry and putting-out system to the centralized factory, as documented by Szostak (1989) and Berg (1994). In our theory, increasing variety of consumer goods and increasing firm size, which are the consequence of a gradual expansion in the market, sow the seeds for process innovation and the economy's take-off. We demonstrate this mechanism in a dynamic general equilibrium model and show that our theory is empirically plausible by deriving its quantitative implications in a model calibrated to the historical experience of England.

The mechanism linking market size to innovation works by changing the price elasticity of demand of non-agricultural consumer products. A larger market allows an economy to sustain a greater variety of consumer goods, making them more substitutable and raising their price elasticity of demand. As a result, mark-ups drop and competition toughens so that firms must become larger to break even. This facilitates process innovation, as larger firms can spread the fixed costs of R\&D over a greater quantity of output. Therefore, innovation endogenously takes off and living standards start to rise only after the market reaches a critical size and competition becomes sufficiently intense. The evolution of markets is thus a precondition for the revolution of industry.

We generate this elasticity effect by embedding Lancaster (1979) preferences into a model of product and process innovation. The Lancaster construct, based on Hotelling's (1929) spatial model of horizontal differentiation, assumes that each household has an ideal variety of an industrial good, identified by its location on a circle. ${ }^{2}$ As goods 'fill up this circle', neighboring varieties become

\footnotetext{
${ }^{1}$ See the Lawrence R. Klein lecture by Galor (2009) for an excellent overview of the achievements of unified growth theory.

${ }^{2}$ Salop (1979) is a similar construct based on Hotelling's (1929) spatial model of horizontal differentiation.
} 
closer substitutes, implying a higher price elasticity of demand and a lower mark-up (Helpman and Krugman, 1985, Hummels and Lugovskyy, 2005). As shown by Desmet and Parente (2010) in a static one-sector model, these preferences imply a positive effect of market size on technological innovation.

Apart from the preference structure, the model is fairly standard and in some aspects simpler than alternative unified growth models. In the spirit of Galor and Weil (2000), it includes a farm sector that produces a subsistence agricultural good, and it assumes parents derive utility from having children. However, in contrast to models that emphasize the role of human capital in economic development, parents do not face a tradeoff between the quantity and the quality of children. ${ }^{3}$ Instead, there is a time-rearing cost to having children that is lower on the farm than in the city. With these features, the model not only generates a rapid transition from Malthusian stagnation to modern growth, but also a structural transformation with a declining agricultural share, and a demographic transition with population growth initially rising with the advent of industrialization and subsequently falling.

The model works as follows. On account of low initial agricultural productivity, the subsistence constraint binds and the economy starts off with most of its population employed in agriculture. Given that so few people live and work in the city and given the fixed operating cost, only a small number of industrial varieties are produced, implying that goods are not particularly substitutable. Mark-ups are high, competition is weak, and hence, firms are small. As a result, firms do not find it profitable to incur the fixed costs of innovation. However, during this Malthusian phase with stagnant living standards, exogenous increases in agricultural TFP allow for increases in the population and a larger urban base, which result in more consumer varieties, tougher competition, and larger firms. Eventually, the industrial market reaches a critical size so that firms become sufficiently large to find process innovation profitable. At this point, firms endogenously lower their marginal costs, and an industrial revolution ensues.

Process innovation in the industrial sector then sets off a demographic transition and a structural transformation. The nonhomotheticity of preferences that follows from the subsistence constraint implies that both rural and urban households have more children as incomes rise. This leads to accelerating population growth: the first phase of the demographic transition. But at the same time, the nonhomotheticity also implies that rising incomes lead to a structural transformation, with a decreasing agricultural employment share. This puts a brake on aggregate fertility

\footnotetext{
${ }^{3}$ See, e.g., Becker et al. (1990), Galor, and Weil (2000), and Lucas (2002).
} 
as urban households have lower fertility than their rural counterparts on account of higher timerearing costs. Eventually, this compositional effect dominates this income effect, and the population growth rate declines: the second phase of the demographic transition.

In the limit, as living standards continue to rise, the subsistence constraint disappears, and the economy converges to constant agricultural and industrial shares of economic activity. Under certain parametric conditions, the population growth rate converges to zero, and the price elasticity of demand approaches a constant. Firms stop increasing in size and the rate of innovation becomes constant. Thus, the economy converges to a modern growth era with a constant positive growth rate of per capita GDP.

To assess the plausibility of our theory, we calibrate the model to the historical experience of England from 1300 to 2000. More specifically, we restrict the model parameters to match pre1700 and post-1950 English observations, and then test the model by examining its predictions corresponding to the 1700-1950 period. We find that the model accounts remarkably well for the main features of England's experience during this transition period. In particular, it closely matches England's growth path, its structural transformation, and its demographic transition. The model also does well in matching the evolution of firm size, a feature specific to the theoretical mechanism we emphasize. The quantitative success of the model, together with independent empirical evidence on the elasticity mechanism provided in Section 2, constitute strong support for our theory.

Our work clearly belongs to the unified growth theory literature. Some of the important papers in this literature are Kremer (1993), Goodfriend and McDermott (1995), Galor and Weil (2000), Hansen and Prescott (2002), Lucas (2002), and Galor and Moav (2002). Although these papers also analyze the transition from Malthusian stagnation to modern growth within a common framework that includes population dynamics, they emphasize very different mechanisms from ours. Moreover, none of these papers models process innovation in the sense of individual firms spending resources to lower their marginal costs, or models product innovation as an increase in the variety of consumer goods. ${ }^{4}$

Our paper also relates to the literature that uses model calibration to gain intuition for the causes of the Industrial Revolution. Important papers in this literature are Harley and Crafts

\footnotetext{
${ }^{4}$ Although some models, such as Goodfriend and McDermott (1995) and Voigtländer and Voth (2006), allow for increasing variety of intermediate goods to capture Smith's (1776) hypothesis that the Industrial Revolution was the consequence of greater specialization, final goods producers continue to be perfectly competitive. As a result, these models not only fail to generate an increasing number of consumer commodities, they are also unable to account for the growing size of firms before and during the Industrial Revolution.
} 
(2000), Stokey (2001), Lagerlöf $(2003,2006)$, and Voigtländer and Voth (2006). As these alternative models are different from ours, they study the effect of alternative factors on the timing of England's takeoff. In our experiments, we consider three factors, each of which has been emphasized by other researchers as being important for England's Industrial Revolution: agriculture productivity (Schultz, 1968, Diamond, 1997), institutions (North and Thomas, 1973, North and Weingast, 1989), and trade (Findlay and O'Rourke, 2007). Our counterfactuals support the view that each of these factors was important for England's development. In particular, our experiments suggest that the Industrial Revolution might have been delayed by several centuries had England had fewer agricultural innovations, slightly inferior institutional arrangements, and more national and international trade barriers.

With respect to the older literature on the Industrial Revolution, our theory echoes back to three branches. The first is the Industrial Organization school, which views the emergence of large firms with supervised production as the key to the Industrial Revolution. Important contributions to this literature are Mantoux (1928), Pollard (1965) and Berg (1994). The second is the Social Change School, which equates the Industrial Revolution to the development of competitive markets. This view is present in the work of Toynbee (1884), Polanyi (1944) and Thompson (1963). The final branch of this older literature emphasizes demand side factors, in particular, the growth of the home market and the development of consumer demand. Here some of the important papers are Gilboy (1932) and McKendrick (1982).

The rest of the paper is organized as follows. Section 2 provides empirical support for the mechanism put forth in this paper, and hence serves as motivation. Section 3 describes the model and characterizes the optimal decisions of agents. Section 4 defines the equilibrium and shows algebraically that under certain conditions the economy converges to a balanced growth path. Section 5 calibrates the model to the historical experience of England, and considers how agricultural productivity, institutions, and trade affected the date of the economy's take-off. Section 6 concludes the paper.

\section{Empirical Motivation}

To motivate our theory, we start by presenting empirical evidence for the underlying mechanism by which greater market size facilitates process innovation. According to this mechanism, increasing variety of consumer goods raises the price elasticity of demand, leading to falling mark-ups and larger firms. The increase in firm size, then, strengthens the incentives of firms to lower their 
marginal costs. Thus, in what follows, we document secular trends in product variety, price elasticity of demand, mark-ups, firm size, and process innovation.

Product innovation Consistent with the historical record, our model leads to both product and process innovation. A growing body of literature argues that product innovation was every bit as important to the Industrial Revolution as process innovation. The creation of new consumer goods, and the increase in varieties, was an essential feature of the Industrial Revolution and the period leading up to it. Berg (2002), for example, in analyzing the nature of British patents for the period 1627-1825 in a subset of industries that includes metal wares, glass, ceramics, furniture and watches, found that over one-quarter of the 1,610 patents specified new products or variations of existing ones. In a narrower study, Griffiths et al. (1992) document that roughly half of the 166 patented and non-patented improvements in the textile industry between 1715 and 1800 concerned product innovation. Similarly, De Vries (1993), using records from probate inventories, documents increasing variety in household durables through the 18th century, despite relatively stagnant wages.

The increase in new consumer goods and varieties is not a post-17th century phenomenon. This is consistent with our theory, in which the expansion in varieties starts before the Industrial Revolution. Weatherwill (1988) argues that the Consumer Revolution peaked between 1680 and 1720. Referring to the 1500-1700 period, Styles (2000) lists a number of products that were either entirely English inventions or drastically remodeled goods from other societies. For example, from continental Europe, Delftware plates, Venetian glass, and upholstered chairs and from Asia and the New World, porcelain, tea, tobacco, sugar, lacquered cabinets, and painted calicos all became available to English consumers in this period.

Price elasticity of demand. Given our mechanism works by changing the price elasticity of demand, the strongest support for our theory would be evidence of a secular rise in the price elasticity of demand. Unfortunately, time series estimates for the price elasticity of individual products do not exist. While uncommon, cross-section studies do support our mechanism. For example, Barron et al. (2008) find that larger markets for gasoline in the United States are associated with more elastic demand, and Hummels and Lugovskyy (2005) document that import demand in larger markets is more responsive to changes in trade costs.

Mark-ups. Our mechanism implies a secular decline in mark-ups associated with the increase in the price elasticity of demand as markets expand. Estimates of mark-ups are more readily available, 
although most studies are contemporary. Short-run studies in the context of business cycles and trade liberalizations strongly suggest that the mark-up is inversely related to market size. Within the trade literature, Tybout (2003) documents that mark-ups generally fall following liberalization, and within the business cycle literature, Chevalier and Scharfstein (1996) and Chevalier et al. (2003) find that mark-ups are countercyclical both at the aggregate and the industry level. To our knowledge, there is only one long-run study on mark-ups. Ellis (2006) estimates mark-ups in the United Kingdom for the period 1870-2003 and finds a 67 percent decline in this 134 year period. Taken together, these studies support the negative relationship between market size and mark-ups implied by our theory.

Firm size. Another implication of our mechanism is that firm size increases with market size. Here, studies are much more abundant, and supportive. A large, extensive literature documents increases in establishment size since industrialization for both England and the United States. For example, Lloyd-Jones and Le Roux (1980) document that the median number of workers in cotton firms in Manchester more than tripled between 1815 and 1841, and Feinstein and Pollard (1988) report that in England production of pig iron per furnace increased from 400 tons in 1750 to 550 in 1790. Using data from the U.S. Census of Manufacturing, Sokoloff (1984) finds more of the same in manufacturing industries over the 19th century, while Granovetter (1984) documents this pattern continued into the 20th century.

Sokoloff's (1984) study is particularly relevant for our theory because it shows that firm size was increasing prior to 1860 in the United States, the starting year of its Industrial Revolution. In a number of industries such as tanning, hats, boots and shoes, the increases in firm size were not associated with mechanization of the production processes. This is consistent with our theory, which predicts that the increase in firm size predates process innovation and the economy's take-off.

The Sokoloff study further supports our mechanism by uncovering a positive correlation between market size, firm size, and the level of industrialization. In particular, the study finds that more densely populated areas had larger firms within a given industry. For example, in the woollen textiles in 1850 average firm size was 38.7 in New England, compared to 14.5 in the Mid Atlantic, and 6.5 in the rest of the country. Additionally, the study finds that more densely populated areas industrialized first. Finally, in those instances where artisan shops where found to coexist with factories during the first half of the 19th century, the study finds that artisan shops were located in rural areas with low population density and high transportation costs. 
There do not seem to be hard numbers of firm size in England predating the Industrial Revolution. Nevertheless, a burgeoning literature on proto-industrialization suggests that firm size increased substantially before the onset of England's takeoff. Proto-industrialization refers to the period between 1500 and 1700, when non-agricultural goods were produced in the countryside for large regional, and even international, markets. It is associated with the rise of the putting-out system, consisting of merchant capitalists who sold inputs to rural households and bought finished goods in return. Under this system merchants controlled and centralized a number of activities, such as marketing and finance, but left production decentralized and in control of rural households. If one interprets the putting-out network as an organization, then the size of organizations was clearly increasing before the Industrial Revolution. The only difference, compared to the factory system, is that not all tasks were performed under the same roof.

Some centralization of production did occur in this period, often employing large workforces. For example, workshops employing over forty parish apprentices existed in Nottingham as early as the 1720s. Indeed, by the time that Hargreaves and Arkwright went to Nottingham with their inventions, the concentration of labor in factories was a fairly familiar idea (Berg, 1994). These proto-factories differed from their followers in that they tended to be limited to specific parts of the production process. For example, in the cotton industry, spinning became centralized, whereas weaving was still left to the cottage industries. Similarly, in the woollen industry, although the artisan system was retained, clothiers used cooperative mills that centralized part of the production process.

Many researchers, particularly Mendels (1972), argue that the rise of the cottage industry was a critical step in the eventual industrialization of the British economy. Indeed, Mendels claims that the proto-industrialization period was a critical transition phase from the feudal world of the Middle Ages to the capitalist world of the modern era. Our work complements this area of research. In our theory increases in firm size not only predate the start of the Industrial Revolution, they are necessary for it to occur.

Firm size and process innovation. The final link in our mechanism is the one from firm size to process innovation. The idea that firm size facilitates process innovation has a long history in economics, going back as far as Schumpeter (1942). There is much empirical evidence supporting this idea. For example, Atack et al. (2008) find that larger firms were more likely to use steam power in the 19th century. Hannan and McDowell (1984) reach a similar conclusion when analyzing the 
relationship between the size of banks and the adoption of ATMs in the 1970s. In examining R\&D expenditures, Cohen and Klepper (1996) find they rise with firm size, with an increasing share of this rise being allocated to process innovation. In the case of the U.S. Industrial Revolution Sokoloff (1988) finds that patenting activity was greater in larger markets, which tended to have larger firms (Sokoloff, 1984).

\section{The Model}

In this section we describe the structure of the model economy. The economy consists of one country, with a rural and an urban area, and zero transportation costs. ${ }^{5}$ Time is discrete and infinite. There are three sectors: a farm sector, an industrial sector, and a household sector. The farm sector is perfectly competitive and produces a single non-storable consumption good. The farm technology uses labor and land and is subject to exogenous technological change. The industrial sector is monopolistically competitive and produces a finite set of differentiated goods, each of which has a unique address on a circle. There is both product and process innovation in the industrial sector. The household sector consists of one-period lived agents, each of whom derives utility from consumption of the agricultural good, consumption of the differentiated industrial goods, and children. For each household, there is a variety of the differentiated good that it prefers above all others. Households earn income by either working in the farm sector or the industrial sector. In addition to working, households use their time to rear children, who constitute the household sector in the next period. In what follows we describe the model structure and the relevant optimization problems encountered by agents in each sector.

\subsection{Household Sector}

Endowments. At the beginning of period $t$ there is a measure $N_{t}$ of households. Each household is endowed with one unit of time, which it uses to rear children and to work in either the farm or the industrial sector. There are no barriers to migration, so that a household is free to work in either sector. Denote by $N_{t}^{f}$ and $N_{t}^{x}$ the measure of households employed in agriculture and industry. Thus,

$$
N_{t}=N_{t}^{f}+N_{t}^{x}
$$

\footnotetext{
${ }^{5}$ A richer version would allow for multiple countries and transportation (or trade) costs. Although this would allow us to analyze the effect of a reduction in transportation (or trade) costs, it would come at the cost of increased analytical complexity.
} 
Each type of household is uniformly distributed on a circle with circumference $\chi$.

Preferences. A household derives utility from the number of children it raises, $n_{t}$, consumption of the agricultural good, $c_{a t}$, and consumption of the differentiated industrial goods, $\left\{c_{v t}\right\}_{v \in V_{t}}$, where $V_{t}$ denotes the set of differentiated goods produced at time $t$. Following the literature on the structural transformation and the demographic transition, each household has an agricultural subsistence constraint, represented by $c_{\bar{a}}$ in the utility function. Departing from the literature on the demographic transition, we assume that household utility does not depend on the quality of children.

A household located at point $\tilde{v}$ on the $\chi$-circumference circle has the following Cobb-Douglas preferences:

$$
U_{\tilde{v}}\left(c_{a t}, n_{t},\left\{c_{v t}\right\}_{v \in V_{t}}\right)=\left[\left(c_{a t}-c_{\bar{a}}\right)^{1-\alpha}\left[g\left(c_{v t} \mid v \in V_{t}\right)\right]^{\alpha}\right]^{\mu}\left(n_{t}\right)^{1-\mu}
$$

where

$$
g\left(c_{v t} \mid v \in V_{t}\right)=\max _{v \in V_{t}}\left[\frac{c_{v t}}{1+d_{v \tilde{v}}^{\beta}}\right] .
$$

The subutility $g\left(c_{v t} \mid v \in V_{t}\right)$ follows Lancaster (1979) by assuming that each household has a variety of the differentiated good that it prefers above all others. This ideal variety corresponds to the household's location on the circle, $\tilde{v}$. The further away an industrial variety $v$ lies from a household's ideal variety, the lower the utility it derives from consuming a unit of variety $v$. In particular, the quantity of variety $v$ that gives the household the same utility as one unit of its ideal variety $\tilde{v}$ is $1+d_{v \tilde{v}}^{\beta}$, where $d_{v \tilde{v}}$ denotes the shortest arc distance between $v$ and $\tilde{v}$, and $\beta>0$ is a parameter that determines how fast a household's utility diminishes with the distance from its ideal variety. ${ }^{6}$

The Lancaster construct is the essential element of our model, as it generates a positive link between effective market size and process innovation through the elasticity of demand. It is not the only construct that generates an elasticity effect, however. For example, Ottaviano et al. (2002) use a quasilinear utility function with quadratic subutility to generate this effect, and Yang and Heijdra (1993) accomplish this with Spence-Dixit-Stiglitz preferences assuming that individual firms internalize the effect of their pricing decision on the aggregate price level. The reasons we adopted Lancaster preferences is that its effect does not depend on whether firms take into account how their price choice affects the aggregate price level, and it implies that demand increases with income. Moreover, the elasticity effect arises in a very intuitive way in the Lancaster setting; the

\footnotetext{
${ }^{6}$ The expression $1+d_{v \tilde{v}}^{\beta}$ is known as Lancaster's compensation function.
} 
bounded product space implies that as varieties 'fill up the circle', neighboring varieties become closer substitutes, implying a higher price elasticity of demand. ${ }^{7}$

Demographics. Households live for one period. Let $n_{t}^{i}$ denote the number of children of a household that is employed in sector $i \in\{f, x\} .{ }^{8}$ The law of motion for the population is then

$$
N_{t+1}=n_{t}^{f} N_{t}^{f}+n_{t}^{x} N_{t}^{x}
$$

There is a time cost of rearing children, denoted by $\tau^{i}$, that depends on the sector $i \in\{f, x\}$ in which the household works. By assumption, this time cost is higher in the city than in the countryside, i.e., $\tau^{x} \geq \tau^{f}$. This assumption is consistent with the historical record. Jones and Tertilt (2006), for example, report that the number of children per woman was higher in non-urban areas than on farms throughout the 19th century, and Williamson (1985) reports that the natural rate of increase for the urban population in 19th century England was lower than in the countryside. The reasons for these regional fertility and population differences are multiple. For one, infant mortality was higher in the city on account of unhealthy living conditions, a problem that persisted in the United States until the advent of urban sanitation systems in the 1920s. For another, laws restricting child labor in 19th century England applied only to factory work (Doepke and Zilibotti, 2005). ${ }^{9}$

The assumption of different time rearing costs is important for generating the second phase of the demographic transition, namely the decline in the population growth rate as the economy approaches the modern growth stage. However, the same pattern could easily be achieved by assuming a secular increase in the time cost of rearing children, which could reflect the increasing role of human capital in the production process. This would be a straightforward way of introducing the quantity-quality tradeoff in parents' fertility decisions. We do not make this assumption because it would require historical data that is not readily available for the purpose of calibrating the model.

\footnotetext{
${ }^{7}$ To our knowledge, Peretto (1998) is the first to establish the link between market size and take-off, adopting the Yang and Heijdra (1993) construct. However, his paper does not belong to the unified growth theory literature since there are no population dynamics. Instead, the increase in the market size is a consequence of an increase in the stock of knowledge.

${ }^{8}$ We need not index the number of children by a household's location on the circle because the fertility choice is independent of location. This is also the case for the agricultural good.

${ }^{9}$ Another reason is that it was possible to simultaneously watch children and tend vegetables in the countryside, but not in the city, where factory work dominated. Of course, the higher number of children in rural areas may also have been due to them being able to work more easily on the farm than in the factory (Rosenzweig and Evensen, 1977, Doepke, 2004). In our model, however, children do not participate in the labor force.
} 
Utility Maximization. The differential cost of rearing children in the city and on the farm implies that household income will be different across sectors in equilibrium, even though households are free to move at the beginning of the period. We therefore distinguish between an agricultural household's income per unit of time worked, $y_{t}^{f}$, and an industrial household's income per unit of time worked, $y_{t}^{x}$. The budget constraint of a household working in sector $i \in\{f, x\}$ is then

$$
y_{t}^{i}\left(1-\tau^{i} n_{t}^{i}\right) \geq c_{a t}^{i}+\sum_{v \in V} p_{v t} c_{v t}^{i}
$$

Maximizing (2) subject to (5) yields the following first order necessary conditions:

$$
\begin{aligned}
c_{a t}^{i} & =\mu(1-\alpha)\left(y_{t}^{i}-c_{\bar{a}}\right)+c_{\bar{a}} \\
\sum_{v \in V_{t}} p_{v t} c_{v t}^{i} & =\mu \alpha\left(y_{t}^{i}-c_{\bar{a}}\right) \\
\tau^{i} n_{t}^{i} & =(1-\mu)\left(1-\frac{c_{\bar{a}}}{y_{t}^{i}}\right)
\end{aligned}
$$

We make assumptions on the technology parameters to ensure that $y_{t}^{i}\left(1-\tau^{i} n_{t}^{i}\right)>c_{\bar{a}}$ for all $t \geq 0$.

To further characterize the optimal consumption of the differentiated goods, we exploit the linearity property of the subutility function (3) with respect to the set of differentiated goods. This implies that each agent consumes a single industrial variety. In particular, an agent buys the variety, $v^{\prime} \in V_{t}$, that minimizes the cost of an equivalent unit of its ideal variety, $p_{v t}\left(1+d_{v \tilde{v}}^{\beta}\right)$. Namely,

$$
v^{\prime}=\operatorname{argmin}\left[p_{v t}\left(1+d_{v, \tilde{v}}^{\beta}\right) \mid v \in V_{t}\right]
$$

Using (7), a household with ideal variety $\tilde{v}$ working in sector $i$ therefore buys the following quantity of variety $v^{\prime}$ :

$$
c_{v^{\prime} t}^{i}=\frac{\mu \alpha\left(y_{t}^{i}-c_{\bar{a}}\right)}{p_{v^{\prime} t}}
$$

Its demand for all other varieties $v \in V_{t}$ is zero.

\subsection{Industrial Sector}

The industrial sector is monopolistically competitive, and produces a set of differentiated goods, each with a unique address on the $\chi$-circumference circle. As in Lancaster (1979), firms can costlessly relocate on the circle. The technology for producing industrial goods uses labor as its only input. The existence of a fixed cost, which takes the form of labor, gives rise to increasing returns. Each firm chooses its price and technology, taking aggregate variables and the choices of other firms as given. There is free entry and exit, so that the number of firms, and varieties, will adjust to ensure all firms make zero profits. 
Production. Let $Q_{v t}$ be the quantity of variety $v$ produced by a firm; $L_{v t}$ the units of labor it employs; $A_{v t}$ its technology level, or production process; and $\kappa_{v t}$ its fixed cost in terms of labor. Then the output in period $t$ of the firm producing variety $v$ is

$$
Q_{v t}=A_{v t}\left[L_{v t}-\kappa_{v t}\right]
$$

Both the fixed labor cost, $\kappa_{v t}$, and the technology level, $A_{v t}$, depend on the firm's rate of process innovation, $g_{v t}$. In particular, similar to Young (1998), the fixed labor cost is given by

$$
\kappa_{v t}=\kappa e^{\phi g_{v t}} .
$$

Thus, there are two components to the fixed cost: an innovation cost, represented by $e^{\phi g_{v t}}$, that is increasing in the size of process innovation, $g_{v t}$, on account that $\phi>0$, and an operating cost, $\kappa$, that is incurred even if there is no process innovation. The firm's technology level, $A_{v t}$, is given by

$$
A_{v t}=\left(1+g_{v t}\right) A_{x t}
$$

where $A_{x t}$ is the benchmark technology in period $t$, taken to be the average technology used by industrial firms in period $t-1$ :

$$
A_{x t}=\sum_{v \in V_{t-1}} \frac{1}{m_{t-1}} A_{v, t-1}
$$

where $m_{t-1}$ is the number of varieties produced in period $t-1$, i.e., $m_{t-1}=\operatorname{card}\left(V_{t-1}\right)$. Therefore, if $g_{v t}=0$, so there is no process innovation, a firm uses the industrial benchmark technology, $A_{x t}$, whereas if $g_{v t}>0$, the firm uses a technology that is $\left(1+g_{v t}\right)$ times greater than the benchmark technology. ${ }^{10}$

Profit Maximization. The fixed operating cost implies that each variety, regardless of the technology used, will be produced by a single firm. In maximizing its profits, each firm behaves noncooperatively, taking the choices of other firms as given. Profit maximization determines the price and quantity to be sold, the number of workers to be hired, and the technology to be operated. As is standard in models of monopolistic competition, firms take all aggregate variables in the economy as given. ${ }^{11}$

\footnotetext{
${ }^{10}$ Thus, we assume complete intertemporal knowledge spillovers. While the existence of this spillover implies a dynamic inefficiency, it is not important to the points we wish to establish. We make the assumption because it is not possible to solve for an equilibrium with asymmetric firms using Lancaster's construct. Without the assumption of complete intertemporal knowledge spillovers, new varieties would start out at a lower technology, and hence there would not be a symmetric equilibrium.

${ }^{11}$ In principle this requires firms to be of measure zero, a condition that is not satisfied. See Desmet and Parente (2010) for a discussion of how firms could be made of measure zero, without changing any of the results.
} 
Using (11), the profits of the firm producing variety $v, \Pi_{v t}$, can be written as

$$
\Pi_{v t}=p_{v t} C_{v t}-w_{x t}\left[\kappa e^{\phi g_{v t}}+\frac{C_{v t}}{A_{x t}\left(1+g_{v t}\right)}\right]
$$

where $w_{x t}$ is the wage in the industrial sector, and $p_{v t}$ is the price of variety $v$.

The problem of the firm producing variety $v$ is to choose $\left(p_{v t}, g_{v t}\right)$ to maximize (15), subject to the aggregate demand for its product, $C_{v t}$. As usual, the profit maximizing price is a mark-up over the marginal unit cost $w_{x t} /\left[A_{x t}\left(1+g_{v t}\right)\right]$, so that

$$
p_{v t}=\frac{w_{x t}}{A_{x t}\left(1+g_{v t}\right)} \frac{\varepsilon_{v t}}{\varepsilon_{v t}-1},
$$

where $\varepsilon_{v t}$ is the price elasticity of demand for variety $v$ :

$$
\varepsilon_{v t}=-\frac{\partial C_{v t}}{\partial p_{v t}} \frac{p_{v t}}{C_{v t}}
$$

The first order necessary condition associated with the choice of technology, $g_{v t}$, is

$$
-\phi \kappa e^{\phi g_{v t}}+\frac{C_{v t}}{A_{x t}\left(1+g_{v t}\right)^{2}} \leq 0
$$

where the strict inequality case in the above expression corresponds to a corner solution, i.e., $g_{v t}=0$.

\subsection{Farm Sector}

The farm sector is perfectly competitive. Farms produce a single, non-storable consumption good, that serves as the economy's numéraire. The farm technology is constant returns to scale, and uses labor and land. There is a measure one of farms.

Production. Let $Q_{a t}$ denote the quantity of agricultural output of the stand-in farm, and $L_{a t}$ the corresponding agricultural labor input. Without loss of generality, we normalize the land owned by the stand-in farm to 1 . The production function is Cobb-Douglas in land and labor with a labor share of $1 \geq \theta>0$, namely,

$$
Q_{a t}=A_{a t} L_{a t}^{\theta}
$$

Agricultural TFP, $A_{a t}$, grows at a rate $g_{a t}>0$ during period $t$, so that

$$
A_{a t+1}=A_{a t}\left(1+g_{a t}\right)
$$


During the Malthusian phase agricultural TFP grows at a constant exogenous rate, $\gamma_{a}>0 .{ }^{12}$ However, once the industrial sector starts innovating, we allow for agricultural TFP growth to accelerate. In particular, we assume that

$$
g_{a t}=\max \left\{\gamma_{a}, \frac{A_{x t}-A_{x t-1}}{A_{x t-1}}\right\}
$$

This assumption is meant to capture the large secular rise in the growth rate of agricultural TFP since the Industrial Revolution, as documented by Federico (2006). Implicitly, it reflects the importance of innovations in the form of farm equipment and synthetic fertilizers originating in the industrial sector. ${ }^{13}$

Profit Maximization. The profit maximization problem of farms is straightforward, as they are price takers. The profit of the stand-in farm is

$$
\Pi_{a t}=A_{a t} L_{a t}{ }^{\theta}-w_{a t} L_{a t}
$$

where $w_{a t}$ is the agricultural wage rate. Farms choose $L_{a t}$ to maximize equation (21). This yields the standard first order condition

$$
w_{a t}=\theta A_{a t}\left(L_{a t}\right)^{\theta-1} .
$$

Total profits (or land rents) are thus,

$$
\Pi_{a t}=(1-\theta) A_{a t}\left(L_{a t}\right)^{\theta}
$$

and profits per unit of time worked, $\pi_{a t}$, are

$$
\pi_{a t}=(1-\theta) A_{a t}\left(L_{a t}\right)^{\theta-1} .
$$

Profits (or land rents) are rebated to the farm households in proportion to their time worked. Hence, total income of a farm household per unit of time worked is the sum of wages per unit of time worked and profits per unit of time worked:

$$
y_{t}^{f}=A_{a t}\left(L_{a t}\right)^{\theta-1}
$$

\footnotetext{
${ }^{12}$ To be consistent with the historical record of a slowly increasing population during the pre-industrial era, agricultural TFP growth must be positive if there are decreasing returns to land.

${ }^{13}$ Alternatively, though at the cost of substantial complexity, the same qualitative results could be obtained by having farms use industrial goods as intermediate inputs, rather than assuming that agricultural TFP growth depends on technological progress in the industrial sector. As technological improvement in industry lowers the relative price of industrial goods, farms would use more industrial intermediate inputs, thereby increasing farm labor productivity. Results for this setup are available from the authors upon request.
} 
Urban households, therefore, do not receive any farm profits. Their income per unit of time worked is

$$
y_{t}^{x}=w_{x t}
$$

\section{Equilibrium}

As is standard in this literature, we focus exclusively on symmetric Nash equilibria. In such an equilibrium, all firms use the same technology, charge the same price, and are equally spaced around the circle. This section defines a symmetric Nash equilibrium for our economy, and explores the limiting properties of the equilibrium. It consists of three parts. In the first part, we derive the aggregate demand for each good in the symmetric case, and use this to simplify the first order profit maximization conditions. In the second part, we define a symmetric equilibrium. In the last part, we establish a set of parametric restrictions that ensure that the economy converges to a balanced growth path.

\subsection{Aggregate Demand}

We first determine the aggregate demand for each industrial good. Demand comes from both types of households. Since in a symmetric Nash equilibrium all varieties produced are equally spaced around the circle, aggregate demand for a given variety depends only on the locations and the prices of its closest neighbors to its right and its left on the circle. Let $d_{t}$ denote the distance between two neighboring varieties in period $t$. This distance is inversely proportional to the number of varieties, $m_{t}$, namely,

$$
d_{t}=\frac{\chi}{m_{t}} .
$$

Since the nearest competitors to the right and to the left of the firm producing variety $v$ are each located at the same distance $d_{t}$ from it, we do not need to differentiate between them, and thus denote each competitor by $v_{c}$ and their prices by $p_{c t}$.

To begin, we derive the aggregate demand of agricultural households for variety $v$. The first step is to identify the location of the household on the circle that is indifferent between buying variety $v$ and variety $v_{c}$. Recall that each household will buy that variety for which the unit cost of an equivalent unit of its ideal variety is lowest. Thus, the agricultural household that is indifferent between buying varieties $v$ and $v_{c}$ is the one whose cost of a quantity equivalent to one unit of its ideal variety in terms of $v$ equals the cost of a quantity equivalent to one unit of its ideal variety in terms of $v_{c}$. Consequently, the agricultural household that is indifferent between $v$ and $v_{c}$ is the 
one located at distance $d_{v t}$ from $v$, where

$$
p_{c t}\left[1+\left(d-d_{v t}\right)^{\beta}\right]=p_{v t}\left[1+d_{v t}^{\beta}\right]
$$

Given this indifference condition applies to agricultural households both to the right and to the left of $v$, the uniform distribution of agricultural households around the $\chi$-circumference circle implies that a share $2 d_{v t} / \chi$ of them consumes variety $v$. Since each household spends $\mu \alpha\left(y_{t}^{f}-c_{\bar{a}}\right)$ on the industrial good, the total demand for $v$ by agricultural households is

$$
C_{v t}^{f}=\frac{2 d_{v t} N_{t}^{f} c_{v t}^{f}}{\chi}=\frac{2 d_{v t} N_{t}^{f}}{\chi} \frac{\mu \alpha\left(y_{t}^{f}-c_{\bar{a}}\right)}{p_{v t}} .
$$

By analogy, total demand by industrial households is

$$
C_{v t}^{x}=\frac{2 d_{v t} N_{t}^{x} c_{v t}^{x}}{\chi}=\frac{2 d_{v t} N_{t}^{x} c_{v t}^{x}}{\chi} \frac{\mu \alpha\left(y_{t}^{x}-c_{\bar{a}}\right)}{p_{v t}}
$$

Given that all firms are spaced evenly in the symmetric equilibrium, it follows that

$$
2 d_{v t}=d_{t}
$$

Aggregate demand for variety $v, C_{v t}$, is the sum of (29) and (30). Hence,

$$
C_{v t}=d_{t}\left(N_{t}^{f} c_{v t}^{f}+N_{t}^{x} c_{t}^{x}\right) / \chi=\frac{d_{t}}{\chi} \frac{\mu \alpha\left(y_{t}^{f} N_{t}^{f}+y_{t}^{x} N_{t}^{x}-N_{t} c_{\bar{a}}\right)}{p_{v t}}
$$

With this demand in hand, we can solve for the price elasticity in a symmetric Nash equilibrium. This involves three steps. First, from (32) it is easy to show that

$$
-\frac{\partial C_{v}}{\partial p_{v}} \frac{p_{v}}{C_{v}}=1-\frac{\partial d_{v}}{\partial p_{v}} \frac{p_{v}}{d_{v}}
$$

Next, by taking the total derivative of the indifference equation (28) with respect to $p_{v t}$, we solve for $\partial d_{v t} / \partial p_{v t}$, and substituting this partial derivative in (33) yields

$$
\varepsilon_{v t}=1+\frac{\left[1+d_{v}^{\beta}\right] p_{v}}{\left[p_{v} \beta d_{v}^{\beta-1}+p_{c} \beta\left(d-d_{v}\right)^{\beta-1}\right] d_{v}}
$$

Finally, we invoke symmetry, i.e., $p_{v t}=p_{c t}$ and $2 d_{v t}=d_{t}$, so that (34) reduces to

$$
\varepsilon_{v t}=1+\frac{1}{2 \beta}\left(\frac{2}{d_{t}}\right)^{\beta}+\frac{1}{2 \beta}
$$

Thus, as the number of varieties increases, the price elasticity of demand increases.

Aggregate demand for the agricultural good is easy to determine. Individual household's demand, (6), implies that aggregate demand is

$$
C_{a t}=\mu(1-\alpha)\left(y_{t}^{f} N_{t}^{f}+y_{t}^{x} N_{t}^{x}-N_{t} c_{\bar{a}}\right)+N_{t} c_{\bar{a}}
$$




\subsection{Symmetric Equilibrium}

We next define a symmetric Nash equilibrium for our economy. Because the decisions of households, industrial firms and farms are all static, the dynamic equilibrium for the model economy is essentially a sequence of static equilibria that are linked through the laws of motion for the population, the benchmark technology in the industrial sector, and TFP in the farm sector.

As is standard, the equilibrium must satisfy profit maximization, utility maximization, and market clearing conditions. It must also be the case that each household is indifferent between working in the farm sector and working in the industrial sector. More specifically, for a household with ideal variety $v$ the utility associated with consumption and children should be the same across sectors:

$$
U\left(c_{v t}^{f}, c_{a t}^{f}, n_{t}^{f}\right)=U\left(c_{v t}^{x}, c_{a t}^{x}, n_{t}^{x}\right) .
$$

Another equilibrium condition requires that firms in the industrial sector earn zero profits. This is a consequence of there being free entry. Thus,

$$
p_{v t} Q_{v t}-w_{x t}\left[\kappa e^{\phi g_{v t}}+\frac{Q_{v t}}{A_{x t}\left(1+g_{v t}\right)}\right]=0
$$

This condition effectively determines the number of varieties and the distance between varieties.

The zero profit condition (38), together with mark-up equation (16) and the elasticity equation in the symmetric equilibrium (35), provide the key to understanding the positive relation between market size and firm size. From the elasticity expression (35) it is apparent that as the number of varieties increases, and the distance between firms decreases, the price elasticity of demand increases. This result is easy to understand: by increasing the number of varieties, the circle becomes more crowded, making neighboring varieties more substitutable. From the price expression (16), it follows that the greater elasticity leads to tougher competition, reducing the mark-up. The zero profit condition (38) then implies that the size of firms, in terms of production, must increase: given the same fixed cost, a firm must sell a greater quantity of units in order to break even. As we will see later, larger firms find it easier to bear the fixed cost of innovation, leading to a positive relation between market size and technological progress.

We now define the dynamic Symmetric Equilibrium.

Definition of Symmetric Equilibrium. A Symmetric Equilibrium is a sequence of household variables $\left\{c_{v t}^{f}, c_{a t}^{f}, n_{t}^{f}, y_{t}^{f}, N_{t}^{f}, c_{v t}^{x}, c_{a t}^{x}, n_{t}^{x}, y_{t}^{x}, N_{t}^{x}\right\}$, a sequence of farm variables $\left\{Q_{a t}, L_{a t}, \pi_{a t}\right\}$, a sequence of industrial firm variables $\left\{Q_{v t}, L_{v t}, p_{v t}, g_{v t}, \varepsilon_{v t}, A_{v t}\right\}$, and a sequence of aggregate variables $\left\{V_{t}, w_{x t}, m_{t}, w_{a t}, d_{t}, N_{t}, A_{x t}, A_{a t}\right\}$ that satisfy 
(i) utility maximization conditions given by (6), (7) and (8).

(ii) farm profit maximization conditions given by equations (18), (22), (24) and (25).

(iii) industrial profit maximization conditions given by (11), (13), (12), (26), (16), (17), and (35)

(iv) market clearing conditions

(a) industrial goods market: equation (11) = equation (32)

(b) industrial labor market:

$$
m_{t} L_{v t}=N_{t}^{x}\left(1-\tau^{x} n_{t}^{x}\right)
$$

(c) farm goods market: equation (18) = equation (36)

(d) farm labor market:

$$
L_{a t}=N_{t}^{f}\left(1-\tau^{f} n_{t}^{f}\right)
$$

(v) aggregate laws of motion for $A_{x t}$ given by (14); for $N_{t}$ given by (4); and for $A_{a t}$ given by (19) and (20)

(vi) zero profit condition of industrial firms given by (38)

(vii) indifference condition of households given by (37)

(viii) population feasibility given by (1)

\subsection{Properties}

We conclude this section by addressing the limiting properties of the model, namely, whether the economy converges to a balanced growth path.

Proposition 1. The economy converges to a balanced growth path with constant technological progress in industry provided that (i) $\left(\frac{1-\mu}{\tau^{f}}-1\right)\left(\frac{1-\alpha}{\alpha}\right)\left(\frac{\tau^{x}}{\tau^{f}}\right)^{\frac{1-\mu}{\mu}}+\left(\frac{1-\mu}{\tau^{f}}-1\right)=0$, (ii) $g_{a t}>0$ for all $t$, and (iii) $\theta$ is sufficiently close to 1 .

Proof. We start by recalling three equilibrium conditions: at all times utility should be equal across farming and industrial households,

$$
\left(y_{t}^{f}-c_{\bar{a}}\right)^{\mu}\left(\frac{1-c_{\bar{a}} / y_{t}^{f}}{\tau^{f}}\right)^{1-\mu}=\left(y_{t}^{x}-c_{\bar{a}}\right)^{\mu}\left(\frac{1-c_{\bar{a}} / y_{t}^{x}}{\tau^{x}}\right)^{1-\mu}
$$


and income should equal expenditure in both sectors,

$$
\begin{gathered}
y_{t}^{f} N_{t}^{f}\left(1-\tau^{f} n_{t}^{f}\right)=\mu(1-\alpha)\left(y_{t}^{f} N_{t}^{f}+y_{t}^{x} N_{t}^{x}\right)+(1-\mu(1-\alpha)) c_{\bar{a}}\left(N_{t}^{f}+N_{t}^{x}\right) \\
y_{t}^{x} N_{t}^{x}\left(1-\tau^{x} n_{t}^{x}\right)=\mu \alpha\left(y_{t}^{f} N_{t}^{f}+y_{t}^{x} N_{t}^{x}\right)-\mu \alpha c_{\bar{a}}\left(N_{t}^{x}+N_{t}^{x}\right) .
\end{gathered}
$$

We now show that $y_{t}^{f}$ in the limit goes to infinity. To do so, it suffices to show that the growth in $y_{t}^{f}$ is strictly positive in each period. Since $y_{t}^{f}=A_{a t} L_{a t}^{\theta-1}$, this amounts to showing that

$$
g_{a t}-(1-\theta) \frac{\dot{L_{a t}}}{L_{a t}}>0
$$

Expression (8) implies that population growth is finite, and therefore growth in the hours worked in agriculture is also finite, so that if $\theta$ is close enough to 1 , expression (44) is satisfied.

Condition (41) implies that if $y_{t}^{f}$ goes to infinity in the limit, then $y_{t}^{x}$ also goes to infinity in the limit. This, in turn, implies that in the limit both types of households have a constant (though different) number of children:

$$
n^{i}=\frac{1-\mu}{\tau^{i}}
$$

where $i \in\{f, x\}$. As the number of children is constant in the limit, the utility indifference condition (41) implies that

$$
\frac{y^{f}}{y^{x}}=\left(\frac{\tau^{f}}{\tau^{x}}\right)^{\frac{1-\mu}{\mu}} .
$$

Moreover, if we divide equation (42) by (43), it follows that in the limit

$$
\frac{y^{f} N^{f}}{y^{x} N^{x}}=\frac{1-\alpha}{\alpha} .
$$

Substituting (46) into (47) then gives the following limit expression:

$$
\frac{N^{f}}{N^{x}}=\frac{1-\alpha}{\alpha}\left(\frac{\tau^{x}}{\tau^{f}}\right)^{\frac{1-\mu}{\mu}}
$$

Thus, the shares of agricultural and industrial households converge to fixed numbers. This together with (45), implies that in the limit population growth is constant. Substituting (48) and (45) into the expression for population growth, $\left(n^{f}-1\right) N^{f} / N+\left(n^{x}-1\right) N^{x} / N$ gives the following expression:

$$
\left(\frac{1-\mu}{\tau^{f}}-1\right) \frac{\frac{1-\alpha}{\alpha}\left(\frac{\tau^{x}}{\tau^{f}}\right)^{\frac{1-\mu}{\mu}}}{1+\frac{1-\alpha}{\alpha}\left(\frac{\tau^{x}}{\tau^{f}}\right)^{\frac{1-\mu}{\mu}}}+\left(\frac{1-\mu}{\tau^{x}}-1\right) \frac{1}{1+\frac{1-\alpha}{\alpha}\left(\frac{\tau^{x}}{\tau^{f}}\right)^{\frac{1-\mu}{\mu}}}
$$

Therefore, if $\left(\frac{1-\mu}{\tau^{f}}-1\right)\left(\frac{1-\alpha}{\alpha}\right)\left(\frac{\tau^{x}}{\tau^{f}}\right)^{\frac{1-\mu}{\mu}}+\left(\frac{1-\mu}{\tau^{f}}-1\right)=0$, as stated in condition (ii), population growth converges to zero. With a constant population, a constant number of children in each sector, and a 
constant share of households employed in the industrial sector in the limit, it follows that the total number of hours worked in industry also converges to a constant.

It is now easy to show that in the limit $g_{v}$ is a constant. The case where $g_{v}=0$ is trivial. Thus, we focus on the case of an interior solution $\left(g_{v}>0\right)$. The zero profit condition, $Q_{v}=\kappa e^{\phi g_{v}} A_{x}\left(1+g_{v}\right)(\varepsilon-1)$, together with the first order condition for technological progress, (17), implies that $g_{v}$ is a positive function of the price elasticity of demand:

$$
g_{v}=\frac{\varepsilon_{v}-1}{\phi}-1
$$

Since the total production of each firm is $\kappa e^{\phi g_{v}} A_{x}\left(1+g_{v}\right)(\varepsilon-1)$ and the total number of hours worked in industry is $\mu N^{x}$ in the limit, it follows that the number of firms is $m=\mu N^{x} /\left(\kappa e^{\phi g_{v}} \varepsilon\right)$, where $m=\chi / d$. Substituting into (35) gives

$$
\varepsilon=1+\frac{1}{2 \beta}\left(\frac{2 \mu N^{x}}{\kappa e^{\phi g_{v}} \varepsilon \chi}\right)^{\beta}+\frac{1}{2 \beta} .
$$

Now re-write (51) as

$$
2 \beta \varepsilon^{\beta+1}-(2 \beta+1) \varepsilon^{\beta}-\left(2 \mu N^{x} / \chi \kappa e^{\phi g_{v}}\right)^{\beta}=0
$$

and take the total derivative of this expression with respect to $g_{v}$. This yields

$$
\frac{\partial \varepsilon}{\partial g_{v}}=-\frac{\beta\left(2 \mu N^{x}\right)^{\beta}(\chi \kappa)^{-\beta} \phi e^{-\phi g_{v} \beta}}{2 \beta(\beta+1) \varepsilon_{t}^{\beta}-(2 \beta+1) \beta \varepsilon^{\beta-1}} .
$$

From (35) we know that $\varepsilon>1$, so that this derivative (53) is strictly negative. Given that (51) implies that $\varepsilon$ is decreasing in $g_{v}$ and (50) implies that $\varepsilon$ is increasing in $g_{v}$, and given that $N^{x}$ is constant in the limit, there is a unique, and constant, $g_{v}$, and thus a unique, and constant, $\varepsilon$. Therefore, if $N^{x}$ is constant, $g_{v}$ is also constant. The economy therefore converges to a balanced growth path with constant growth in the industrial sector.

In Proposition 1 we have shown that if population growth converges to zero, the economy converges to a balanced growth path with constant technological progress in the industrial sector. (This constant rate of technological progress may be zero.) Next, we show that the rate of technological progress in the limit is an increasing function of the balanced growth path population, $N$, and a decreasing function of the cost of innovation, $\phi$.

Proposition 2. Technological progress in the balanced growth path is an increasing function of population, $N$, and a decreasing function of the innovation cost parameter, $\phi$. 
Proof. As argued in the proof of Proposition 1, on the balanced growth path, expressions (50) and (51) determine the rate of technological progress and the price elasticity of demand. Expression (50) does not depend on $N^{x}$, whereas expression (51) does. To see this, re-write (51) as (52) and totally differentiate, keeping $g_{v}$ fixed. This gives

$$
\frac{\partial \varepsilon}{\partial N^{x}}=\frac{\left(2 \mu / \chi \kappa e^{\phi g_{v}}\right)^{\beta} \beta\left(N^{x}\right)^{\beta-1}}{2 \beta(\beta+1) \varepsilon^{\beta}-(2 \beta+1) \beta \varepsilon^{\beta-1}}
$$

Since $\varepsilon>1$, the above partial derivative is strictly positive, so that an increase in $N^{x}$ leads to a greater elasticity of demand for any given $g_{v}$. Recall that expression (50) implies that the elasticity is upward sloping in $g_{v}$, whereas expression (51) implies that the elasticity is downward sloping in $g_{v}$. This, together with the fact that a greater value of $N^{x}$ causes an upward shift in expression (51), allows us to conclude that $g_{v}$ is increasing in $N^{x}$. Since $N^{x}$ is a fixed share of $N, g_{v}$ is therefore also increasing in the size of the population.

To show that $g_{v}$ is decreasing in $\phi$, we use a similar argument. Re-write (51) as (52) and totally differentiate with respect to $\phi$, keeping $N^{x}$ and $g_{v}$ constant. This gives

$$
\frac{\partial \varepsilon}{\partial \phi}=-\frac{\beta\left(2 \mu N^{x}\right)^{\beta}(\chi \kappa)^{-\beta} g_{v} e^{-\phi g_{v} \beta}}{2 \beta(\beta+1) \varepsilon^{\beta}-(2 \beta+1) \beta \varepsilon^{\beta-1}}
$$

Since $\varepsilon>1$, the above partial derivative is strictly negative, so that an increase in $\phi$ leads to a smaller elasticity of demand for any given $g_{v}$. By analogy with the above argument, this implies that $g_{v}$ is decreasing in $\phi$.

The intuition for the positive relation between the size of the limit population and the balanced growth path rate of technological progress is straightforward. A greater population leads to a larger number of households employed in the industrial sector. The greater size of the industrial sector, and the larger number of varieties produced, imply lower mark-ups and tougher competition. To break even, industrial firms must become larger. These larger firms then endogenously choose to innovate more. This is obvious from the first order condition on technology choice, (17), which exhibits two effects: an increase in innovation raises a firm's fixed cost and lowers its marginal cost. The first (negative) effect is independent of firm size, whereas the second (positive) effect is increasing in firm size. As a result, larger firms innovate more.

Propositions 1 and 2 have important implications. Starting off in a situation with no technological progress in industry, two situations can arise. If population reaches the critical size for take-off before population growth converges to zero, we will get an industrial revolution, and the economy will converge to a balanced growth path with strictly positive technological progress 
in industry. However, if population growth converges to zero before that critical size is reached, we have an industrialization trap, and the industrial sector never innovates. As Proposition 2 suggests, this industrialization trap becomes increasingly likely, the higher is $\phi$. This is easy to see when considering the extreme case of $\phi$ being infinite. Then obviously there will never be any take-off. ${ }^{14}$

The result that population growth must be zero in order for there to be a balanced growth path reflects the presence of a scale effect in the model. Empirically, the question of whether there are scale effects (in growth rates) in the postwar period is controversial. For example, at the aggregate level, Jones (2005) finds no evidence of scale effects, whereas Alesina et al. (2000) do, once they control for trade openness. Likewise, at the micro level, Laincz and Peretto (2006) conclude there are no scale effects, whereas Backus et al. (1992) report scale effects in the manufacturing sector.

It is not this paper's intent to weigh in on this debate. However, even if scale effects are not supported empirically, the limiting property of the model should not be viewed as a failure of our theory. There are several ways to eliminate the scale effect in the limit while still preserving the mechanism for the economy's take-off. One is to employ the Yang and Heijdra (1993) construct as in Peretto (1999). Another is to follow Kortum (1997) and assume that the cost of finding each new idea becomes increasingly difficult. Using either of these two approaches would not significantly change the qualitative properties of the model.

\section{$5 \quad$ Numerical Experiments}

In this section, we calibrate the model to the historical record of England over the period 1300-2000, and use the calibrated structure to examine how the timing of the industrial revolution is affected by a number of factors emphasized by other researchers as being important for understanding why England was the first country to develop.

\subsection{Calibration}

The calibration strategy is to assign parameter values so that the model equilibrium is characterized initially by a Malthusian-like era and in the limit by a modern growth era. Empirically, the key observations of the Malthusian era targeted in the calibration are: (i) a constant living standard, (ii) a constant rate of population growth, and (iii) a dominant share of agricultural activity in the

\footnotetext{
${ }^{14}$ We do not call this a development trap because unless we make assumptions that $\gamma_{a}$ in equation (21) goes to zero in the limit, then there will be increases in agricultural output per person in the industrialization trap.
} 
economy. Empirically, the key observations of the modern growth era targeted in the calibration are: (i) a constant, positive rate of growth of per capita GDP, and (ii) a dominant share of industrial activity in the economy. Theoretically, for the model to generate a modern growth era, the population growth rate must converge to zero in the limit. This is another key restriction in the calibration exercise.

Table 1: Parameter Values

\begin{tabular}{|c|c|}
\hline Parameters & Comments/Observations \\
\hline \multicolumn{2}{|l|}{ 1. Population } \\
\hline$N_{0}=5$ million & average estimate of population in England in 1300 \\
\hline \multicolumn{2}{|c|}{ 2. Industrial technology parameters } \\
\hline $\begin{array}{l}\phi=4.0 \\
\chi=209,537\end{array}$ & $\begin{array}{l}\text { normalization } \\
\text { median percentage of ratio of non-production to production work- } \\
\text { ers in US manufacturing outside central offices (Berman et al., } \\
\text { 1994) } \\
\text { limiting growth of per capita GDP between } 1.5-2.0 \% \text { (Maddison, } \\
2001 \text { ) } \\
\text { firm size of } 2 \text { workers in } 1300\end{array}$ \\
\hline \multicolumn{2}{|c|}{ 3. Agricultural technology parameters } \\
\hline $\begin{array}{l}A_{a 0}=179 \\
\gamma_{a}=0.0095 \\
\theta=0.71\end{array}$ & $\begin{array}{l}\text { constant agricultural living standard in pre- } 1500 \text { era } \\
\text { pre-1500 average annual population growth rate of } 0.025 \% \text { (Mad- } \\
\text { dison, 2001) } \\
1700 \text { labor share in agriculture estimate (Clark, 2002a, Hayami } \\
\text { and Ruttan, 1971) }\end{array}$ \\
\hline \multicolumn{2}{|c|}{ 4. Preference parameters } \\
\hline $\begin{array}{l}c_{\bar{a}}=1.55 \\
\alpha=0.98 \\
\mu=0.9125 \\
\beta=0.50\end{array}$ & $\begin{array}{l}\text { agricultural share of employment in } 1600 \text { (Allen, 2000) } \\
2 \% \text { limiting share of agriculture's share of employment (Mitchell, } \\
1988 \text { ) } \\
\text { total fertility rate in } 2007 \text { for London of } 1.80 \text {. } \\
\text { mark-up estimates between } 5-15 \% \text { in the limit (Jaimovich and } \\
\text { Floetotto, 2008) }\end{array}$ \\
\hline \multicolumn{2}{|c|}{ 5. Child rearing parameters } \\
\hline $\begin{array}{l}\tau^{f}=0.021 \\
\tau^{x}=0.095\end{array}$ & $\begin{array}{l}\text { zero population growth in the limit } \\
\text { estimates between } 7.5-15 \% \text { per household (de la Croix and Doepke, } \\
2004 \text { ) }\end{array}$ \\
\hline
\end{tabular}

Before assigning parameters, it is necessary to identify the empirical counterpart of a model period, and the beginning year. Given that households live for one period during which they raise their offspring, it is reasonable to interpret a period as the time that elapses between generations. In models that employ a two-period generational construct, a period is typically assigned a length of 35 years. However, since our model is one of the last millennium and as life expectancies were far 
shorter before the 20th century, we choose 25 years for the period length. The first model period is identified with the year 1300. This choice is primarily motivated by data availability.

Table 1 lists the parameter values and provides brief comments on how each was assigned. A few additional words are warranted in the case of some of the assignments. First, the target for firm size in 1300 is set to 2 workers. This number is not based on an exact estimate, but on the idea that a typical workplace in 1300 probably consisted of a master craftsman and an apprentice. Second, although the initial population is set to the average estimate for England in 1300, it could easily have been normalized to some other number. The reason is that the calibrated value for the circumference of the variety circle is set to match an initial firm size of 2 workers. As a result, a change in the initial population would simply translate into a change in the circumference of the variety circle, without affecting any of the quantitative results. ${ }^{15}$ The unimportance of the initial population size makes it clear that in our theory firm size is the key determinant of innovation. That is, population size only matters in as far as it affects firm size.

Another assignment that requires some explanation is the labor share parameter in agriculture. The empirical counterpart of the share of agricultural output that goes to labor has increased steadily over the last four centuries. Labor's share in agriculture was 67 percent in 1600 according to Clark (2002a) and 86 percent in 1950 according to Hayami and Ruttan (1971). As the model does not allow for this secular rise, the labor share parameter, $\theta$, is set to the 1700 trend-value based on a linear interpolation of the 1600 and 1950 estimates. ${ }^{16}$ Lastly, although the time cost of rural child rearing is not set to match time use data, the value for $\tau^{f}$ implied by the zero growth condition is consistent with estimates of child rearing costs in rural areas, such as by Ho (1979) in the case of the Philippines. ${ }^{17}$

Figures 1-6 present the equilibrium path for the model economy from 1300 to 2000 along six dimensions: technological progress in the industrial sector, the growth rate of GDP per capita, the growth rate of population, agriculture's share of employment, the relative price of industrial goods, and firm size in terms of number of workers. Where appropriate and available, we plot the real world counterparts of the data for the English economy. Growth rates in the figures are

\footnotetext{
${ }^{15}$ The quantity of land must also be changed in proportion to the population change in order generate the same equilibrium.

${ }^{16}$ We have redone the calibration to match the post-1950 estimate, and the equilibrium properties are quantitatively the same.

${ }^{17}$ Ho (1979) finds that child rearing takes $15 \%$ of a woman's time (or $7.5 \%$ of parents' time) for an average of 3.6 children present in the household at the time of the survey. This amounts to $2.1 \%$ of parents' time per child, identical to the value of $\tau^{f}$ used in the calibration.
} 


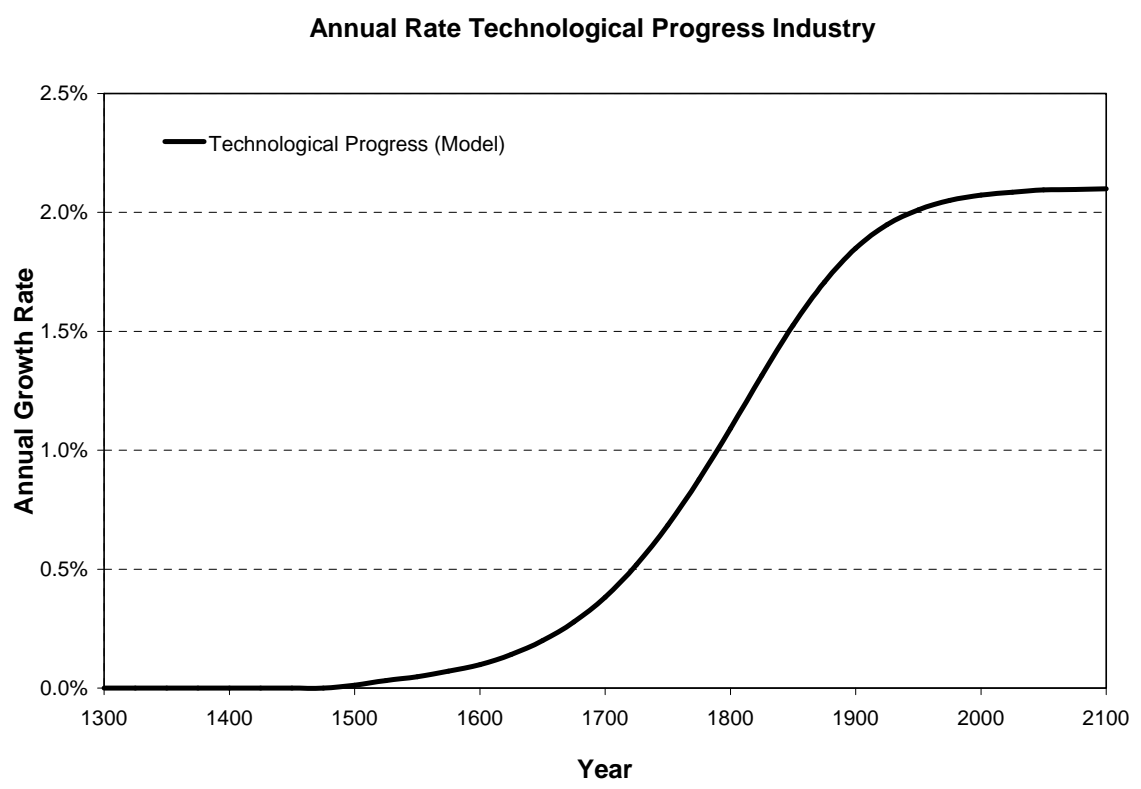

Figure 1: Technological Progress (Benchmark)

expressed in annual terms. Data on the growth rates of GDP per capita and population are based on Maddison (2001). Data on the agricultural share of employment come from Allen (2000) for the 1300-1800 period, and thereafter from Mitchell (1988). ${ }^{18}$ Data on relative prices are from Yang and Zhu (2008) for the 1700-1909 period, and are then extended through 1938 using the Sauerbeck price series in Mitchell (1988). ${ }^{19}$ Data on firm size pertain to the United States, given the absence of historical time series for England. They measure establishment size in the manufacturing sector, and the sources are Atack and Bateman (2006) prior to 1970 and the U.S. Census of Manufactures for more recent years.

In terms of population growth, output growth, and agriculture's share of economic activity, the calibrated model matches the historical experience of the English economy extremely well. We emphasize that we did not calibrate the model economy to England's Industrial Revolution: we calibrated to the pre-1700 Malthusian era and the post-1950 modern growth era. Thus, the model's ability to match the starting date of England's Industrial Revolution as well as its growth rate of per

\footnotetext{
${ }^{18}$ Clark (2002b) also provide estimates for agriculture's share of employment for the 1500-1700 period for England. They are lower than those of Allen (2000), and can be interpreted as a lower bound. Calibrating to Clark's figures is not a problem. Another alternative is to use the estimates of Allen (2000) for the rural population, rather than the agricultural population. Those figures provide an upper bound.

${ }^{19}$ We were not able to extend the British data on relative prices beyond 1938. For the United States, however, the relative price of manufactured goods has shown no secular trend in the 20th century. This is consistent with the model's prediction of a constant relative price in the balanced growth path.
} 


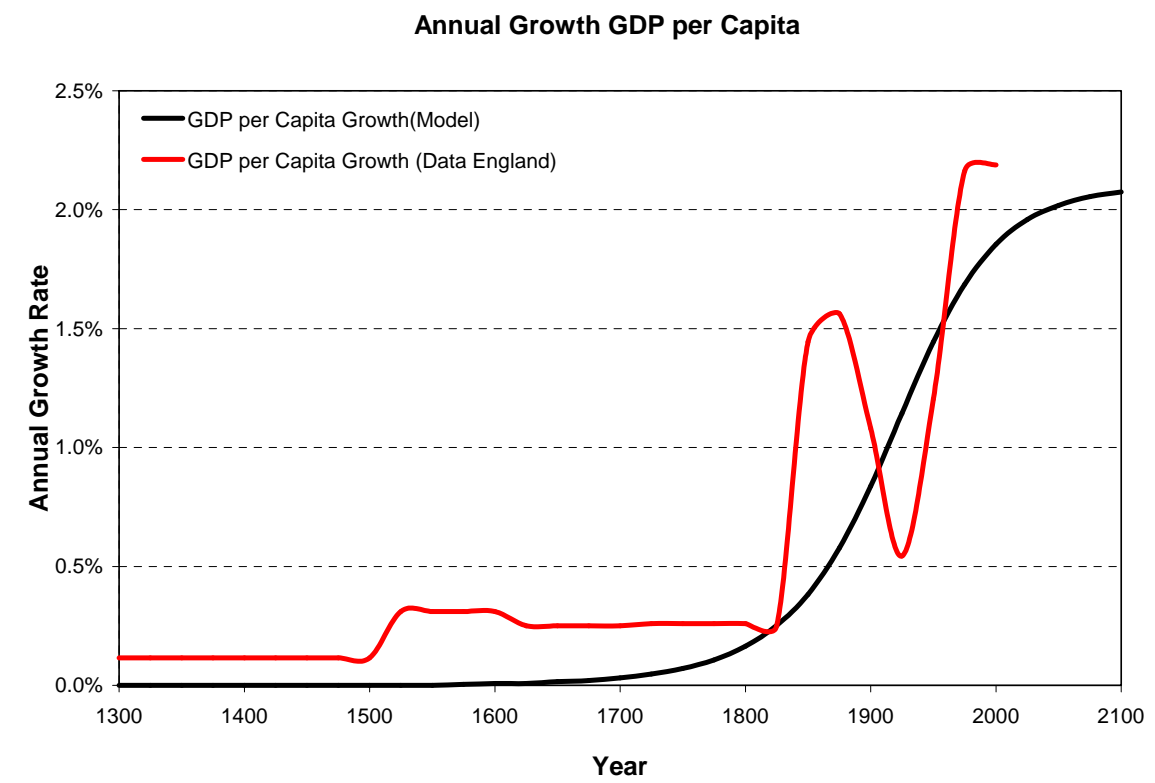

Figure 2: Growth GDP per Capita (Benchmark)

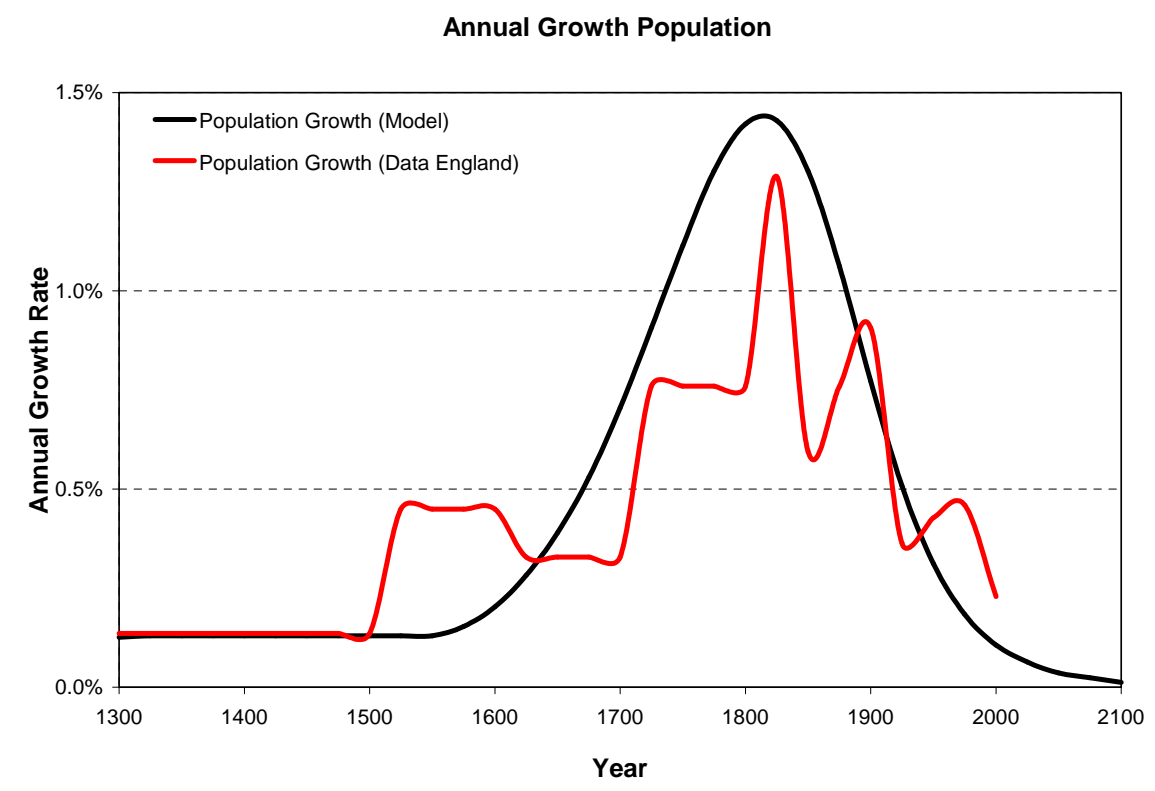

Figure 3: Growth Population (Benchmark) 


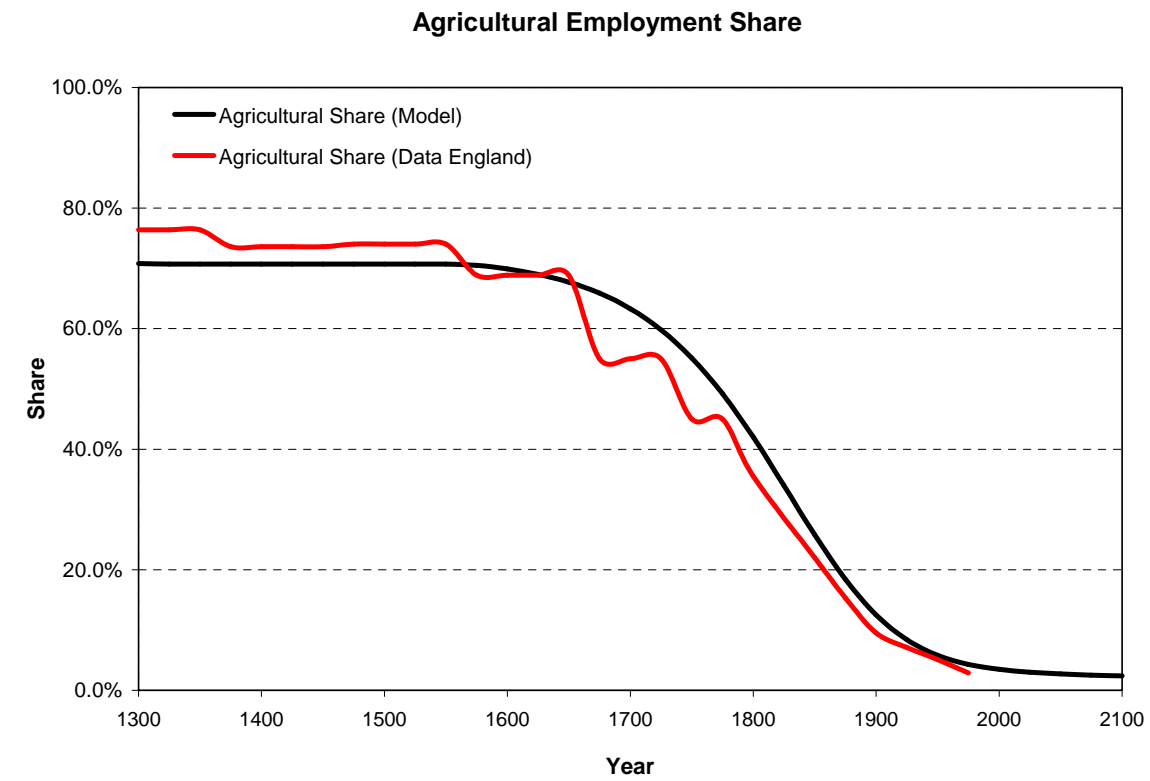

Figure 4: Agricultural Employment Share

Relative Price Industrial Goods

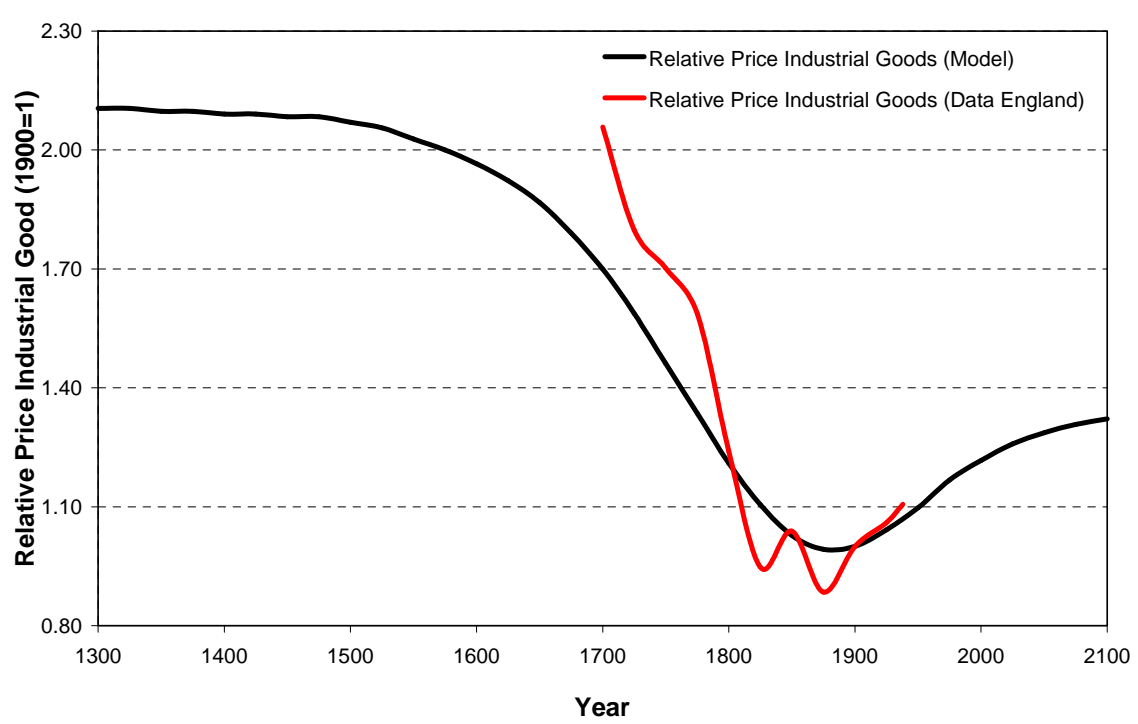

Figure 5: Relative Price Industrial Goods (Benchmark) 


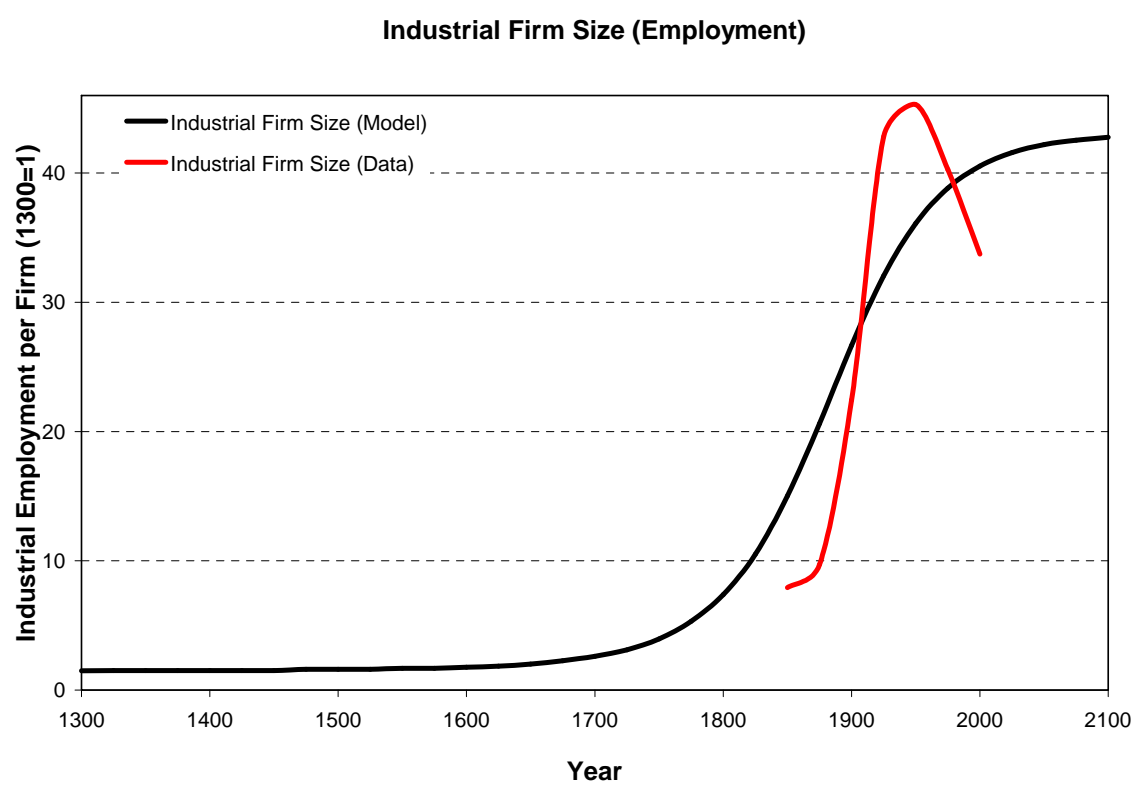

Figure 6: Industrial Firm Size (Benchmark)

capita GDP, its population growth rate, and its agriculture's share of employment for the period 1750-1950 represents four successful tests of our theory.

In terms of the specific mechanism underlying our theory - the relation between market size, firm size and innovation - the calibrated model also does well. Both in the data and in the calibration the number of production workers per establishment increases four-fold between 1850 and 2000. It appears from Figure 6 that the model is slightly off in the timing of this increase. However, it is important to note that the data in Figure 6 pertain to the United States. Given that the Industrial Revolution in the England started between 50 and 100 years earlier than in the United States, the model's prediction for the timing of the increase in firm size seems about right.

Although the model closely matches the growth rate of England's population from 1300 to 2000, it does not perform as well in matching English urban and rural fertility rates over this period. In particular, the model predicts a secular rise in both fertility rates. This counterfactual prediction should not, however, be viewed as a failure of the theory, as it can be easily amended by assuming increasing child rearing time costs in both sectors.

On other dimensions that are specific to our theoretical mechanism, comparisons with the data are harder. For example, the predicted decline in mark-ups of 7 percent in our model is lower than the 67 percent computed by Ellis (2006) for the period 1870-1985. However, these numbers 
are not directly comparable, since the Ellis figure was not calculated from price and wage data, but instead was estimated within a specific model economy using a state-space approach. As for the increase in the number of consumer varieties predicted by the model, there are no specific estimates in the data to compare our results to. In addition, recall that in our theoretical model the number of varieties coincides with the number of firms. Therefore, in as far as we match the size of firms and the number of workers in the industrial sector, we are also matching what corresponds to the number of varieties in our model. ${ }^{20}$

Whereas the intuition for the model's take-off and limiting properties are clear, the transitional dynamics require some further discussion. The defining feature of the industrial revolution is the acceleration in the innovation rate. This acceleration is due to a variety of factors. Once the industrial sector starts to innovate, incomes rise. This makes the subsistence constraint less binding, shifting demand to industrial goods. Rising incomes also lead to higher population growth, further increasing the size of the industrial market. Additionally, recall that agricultural TFP growth goes up in response to industrial innovation, thus encouraging more workers to move from the farm to the city. Taken together, these different forces imply a growing industrial sector, and thus a rising rate of innovation.

With the exception of the population growth rate and the relative price of industrial goods, the secular trends are monotonic. The non-monotonicity of the population growth rate is the consequence of the differential cost of rearing children and the rising share of the urban population. The non-monotonicity of the relative price reflects the behavior of the ratio of the industrial wage rate to technology, $w_{x} /\left[A_{x}\left(1+g_{v}\right)\right]$, which affects the price charged by an industrial firm as shown in equation (16). This ratio declines throughout much of the transition period from Malthusian stagnation to modern growth, and then increases slightly before converging to a constant. This pattern arises because the absolute size of the agricultural population initially increases, then decreases, and eventually stabilizes as the economy converges to a constant population. Because land is a fixed factor, this implies that agricultural household income initially grows slower, then faster, and eventually at the same rate as technical progress in industry. Since households must be indifferent between working in both sectors, the evolution of industrial household income is similar: it first grows more, than less, and eventually at the same rate as technological progress.

\footnotetext{
${ }^{20}$ The coincidence of number of firms and number of varieties is natural if one re-interprets the Lancaster variety model as a spatial model, in which goods are differentiated by location. That being said, there are of course ways to introduce a distinction between the number of firms and the number of varieties. For example, we could modify the model to allow for the introduction of new goods through the introduction of new variety circles.
} 
This explains the non-monotonic behavior of this ratio, and the relative price of industrial goods.

In summary, the model is able to predict the main features of England's Industrial Revolution, in particular, its demographic transition, its structural transformation, and its rate of growth. It also closely matches the evolution of firm size. This is important, as the change in the size of firms over time is specific to the theoretical mechanism we emphasize. In light of the overall success of the model, it is informative to investigate how factors that are likely to differ across societies affect the timing of the industrial revolution. This is the subject we analyze next.

\subsection{The Timing of the Industrial Revolution}

In this section we explore how certain parameters affect the timing of the industrial revolution. Since numerous researchers have emphasized the role of agriculture for long run development, we consider how the start of the industrial revolution is affected by the economy's initial level of agricultural TFP, $A_{a 0}$, and its growth rate, $\gamma_{a}$. Additionally we examine how the economy's take-off is affected by the fixed cost parameters, $\kappa$ and $\phi$. This we do because operating costs and R\&D costs can be affected by institutions, and because numerous researchers have argued that institutional developments were critical for England's economic success. Finally, we examine how the economy's take-off is affected by cutting its initial population and land endowment in half. This experiment aims to capture the effect of trade restrictions, another factor that has been strongly emphasized in the literature. While we cannot analyze the effect of trade restrictions in the sense of a small increase in transportation costs, halving an economy's initial population and land endowment is equivalent to taking two identical open economies and closing them to trade.

Before reporting the findings, we emphasize that these experiments are not intended to address the question why the industrial revolution of some country other than England happened a certain number of years later. International spillovers from early starters to later followers have clearly been important in understanding the development path of the latter by accelerating their escape from Malthusian stagnation. A multi-country model with international spillovers is not something studied in this paper. To be clear, the following experiments are limited to analyzing how different initial conditions would have affected the timing of England's take-off.

\subsubsection{Agricultural Productivity}

How much later would the Industrial Revolution in England have occurred if agricultural productivity had been lower? Several researchers, such as Schultz (1968) and Diamond (1997), have argued 


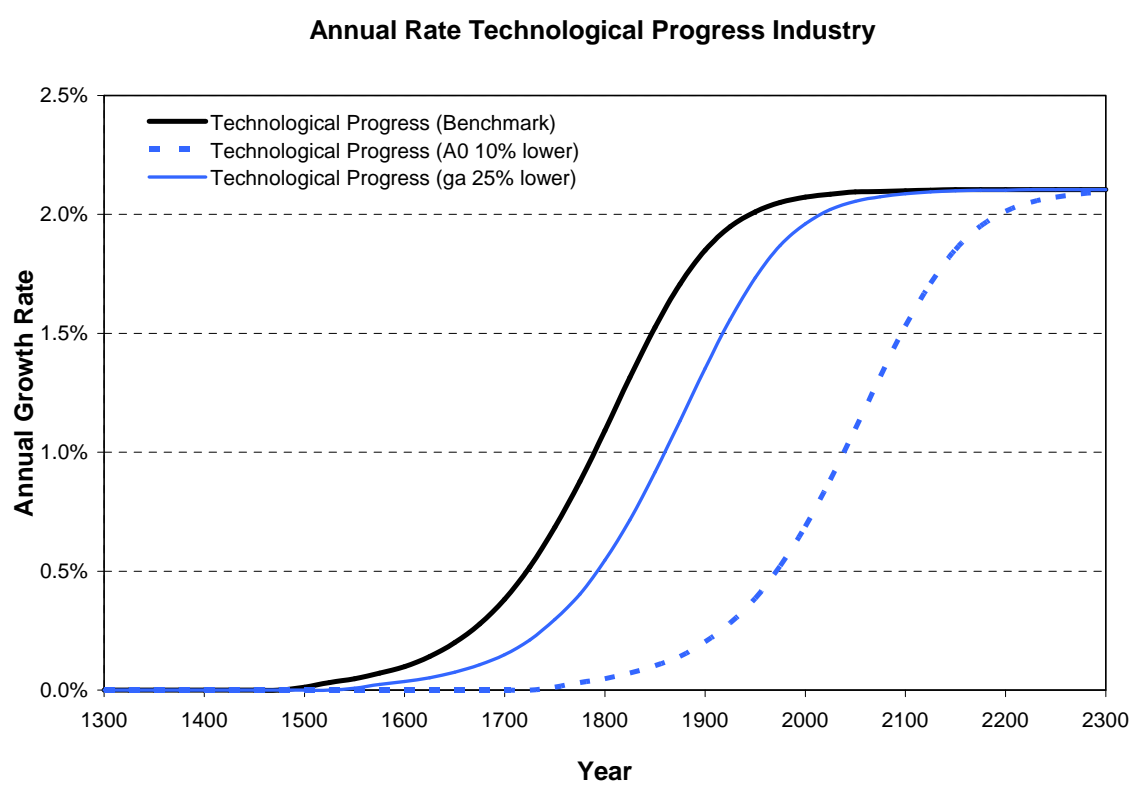

Figure 7: Effect of Lower Agricultural TFP on Timing of Industrial Revolution

that high agricultural productivity is a necessary condition for long-run development. Towards the goal of answering this question, we conduct two experiments. The first of these lowers the value of initial agricultural TFP, $A_{a 0}$, by 10 percent, whereas the second reduces the growth rate of agricultural TFP during the pre-industrial period, $\gamma_{a}$, by 25 percent. The results for process innovation are displayed in Figure $7 .^{21}$

Not surprisingly, a lower starting level of agricultural TFP delays the onset of the industrial revolution. This happens because population size is smaller in the Malthusian era, implying fewer differentiated goods and smaller industrial firms at any date. The size of the delay, 250 years, associated with the 10 percent decline in agricultural TFP, may seem surprising, but it is not. With the calibrated growth rate of agricultural TFP of 0.038 percent per annum in the benchmark case, it takes slightly more than 250 years for agricultural TFP to rise by 10 percent. In other words, the 250 year delay found in this experiment reflects the time it takes agricultural TFP to reach the initial benchmark level. The size of the delay, however, does suggest that a modest increase in agricultural TFP can be extremely important for an economy's takeoff.

For similar reasons, a lower rate of agricultural TFP growth also delays the onset of the industrial revolution. For an annual growth rate of 0.029 percent (instead of 0.038 percent), the

\footnotetext{
${ }^{21}$ In these experiments, we adjust the initial population so that the economy continues to display a Malthusian era steady state.
} 


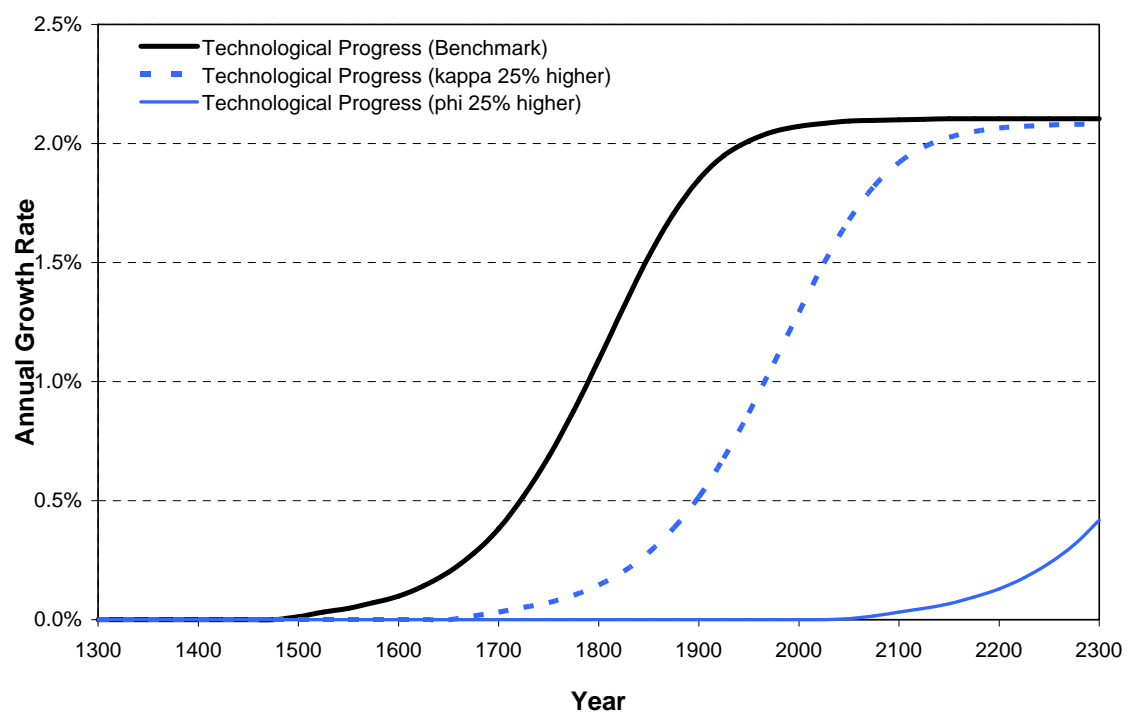

Figure 8: Effect of Worse Institutions on Timing of Industrial Revolution

start is only delayed by about 75 years. This shorter delay makes sense: to achieve the same accumulated growth as with the benchmark TFP growth of 0.038 percent over 250 years takes about 75 years more with a TFP growth of 0.029 percent.

\subsubsection{Policy and Institutions}

We next explore how the timing of England's Industrial Revolution was affected by institutional factors, a main theme in the research of North and Thomas (1973), North and Weingast (1989), and Ekelund and Tollison (1981). In the real world, the fixed costs firms incur to operate and to innovate depend to a large extent on institutions and policy. We therefore interpret larger values for the fixed cost parameters, $\kappa$ and $\phi$, as worse institutions and policies. Recall that $\kappa$ is the fixed cost of operating the benchmark technology, whereas $\phi$ determines how much the fixed cost increases when better technologies are adopted.

Figure 8 shows what happens when we increase each fixed cost parameter separately by 25 percent. In the case of a higher fixed operating cost $\kappa$, the industrial revolution is delayed by 175 years; in the case of a 25 percent higher fixed adoption cost $\phi$, the industrial revolution is delayed by 550 years. Whereas raising either parameter delays the start of the industrial revolution, the intuition for the delays is different. In the case of $\kappa$, worse policies or institutions imply less varieties produced in the economy, meaning the elasticity of demand is lower and innovation is 


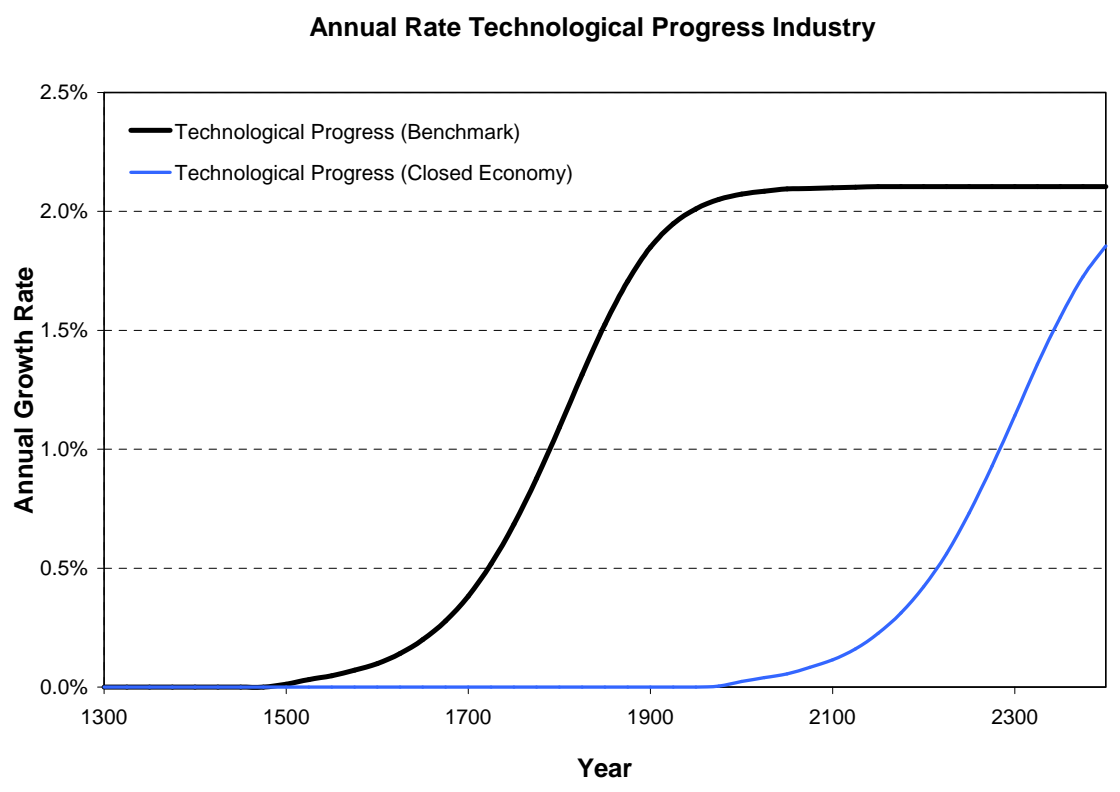

Figure 9: Effect on Trade Restrictions on Timing of Industrial Revolution

unprofitable. In the case of an increase in $\phi$, the number of varieties and firm size are unaffected. However, because the cost of process innovation is higher, firms have to be larger to find innovation profitable.

Clark (2003) has criticized institutional based theories on account that changes in British institutions do not time very well with the start of the Industrial Revolution. The Glorious Revolution, of course, occurred in 1688, but the Industrial Revolution did not start for another 100 years. This experiment suggests that Clark's (2003) timing-based argument is not justified. More to the point, our experiment shows that changes in a country's institutions that affect operating and innovation costs are important for the timing of an economy's take-off, even though the date of the take-off may lag these changes by several centuries.

\subsubsection{Trade}

Both international and intranational trade have been identified by numerous authors, such as Findlay and O'Rourke (2007) and Szostak (1991), as being important for England's early development. In light of this, we end this section by considering the effect of trade restrictions on the timing of take-off. Although we cannot analyze the effect of an incremental change in trade restrictions, we can easily compare free trade with autarky. Indeed, taking two identical open economies and closing them to trade is identical to cutting the economy's population and land mass in half. Al- 
though marginal changes in transport or trade costs may be empirically more relevant, comparing free trade to autarky is, nevertheless, informative and provides an upper bound of the effect of trade on development.

Figure 9 shows the effect of cutting the country's size and population in half on the process innovation. ${ }^{22}$ Not surprising, the start of the industrial revolution is dramatically delayed, approximately by 450 years. This experiment suggests an important role played by trade in understanding England's long run development.

\section{Conclusion}

This paper has put forth a unified growth theory that is consistent with the well documented increase in the variety of consumer goods that preceded the Industrial Revolution and the gradual shift in the workplace to larger and more centralized production units. We have shown that our theory is plausible by calibrating the model to England's long-run development, and by providing empirical support at the firm and the industry level for the mechanism that underlies our theory. We have also examined in the calibrated model the role of various factors emphasized by other researchers as being important for the timing of England's industrialization. A virtue of our theory is that this disparate set of factors all affect the date at which the economy industrializes by changing the price elasticity of demand.

Relative to other unified growth theories, this paper's novelty lies in the mechanism by which larger markets bring about an economy's take-off, rather than in the idea that an expansion of markets is critical for industrialization. The importance of market size is, of course, an old idea, prevalent in the writings of Adam Smith (1776), and a cornerstone of a number of recent unified growth theories such as Goodfriend and McDermott (1995) and Voigtländer and Voth (2006). However, in contrast to our mechanism, these alternative theories typically assume some type of production externality. Our theory does not rely on any type of spillover.

Despite its long history, the view that market size was critical for determining the timing of the Industrial Revolution is not without controversy. Crafts (1995), for example, has criticized population-based theories on account that larger countries have not grown faster in the postwar period. This misses the point in the sense that population size is not an adequate measure of market size. In our theory the effective size of the industrial market, and not population size per

\footnotetext{
${ }^{22}$ In this case we do let the change in initial population affect the initial firm size. If not, the initial population size would not matter, as explained before.
} 
se, is the key determinant of an economy's take-off. Whereas the effective size of the industrial market depends on a country's total population, it is also affected by transport costs, internal and external trade barriers, agricultural productivity, income levels, and institutions.

Compared to other European countries, the evidence suggests that on the eve of the Industrial Revolution markets in England were more national in scale. For example, using spatial variations in grain prices, Shiue and Keller (2007) show that England was more integrated than the rest of Europe. One reason for this were the vast improvements in road and canal infrastructure during the 17th and 18th centuries. By the 1750s, the average coach in England traveled about 100 kilometers per day, doubling the speed in France (Szostak, 1991).

But did the expanding market size in England also imply that the market for industrial goods was larger than in other countries? Although more research is needed to answer this question, the evidence suggests it was. We know that agricultural productivity in England was twice as large as in France (Allen, 2000), and that England had a higher income per capita. It was also far more urbanized with 23 percent of the population in England living in cities, compared with only 13 percent in France (Allen, 2000). The only advantage of France was its larger population. However, even if we make the extreme assumption that French industrial markets were national in scale, the seller side of the industrial market in France (roughly speaking, the urban population) was not any greater than in England, approximately 2 million people. Comparisons with other continental European countries are equally favorable to England.

As for China, economic historians consider the relevant comparison to be with the Yangtze Delta, China's most vibrant region in the 18th century. Although the Yangtze Delta had a much larger population than England, its income per capita and its agricultural productivity were not only lower than England's, but they had been trending downwards since the 17th century, prompting Allen (2006) to conclude that the Yangtze Delta could best be described as an economy "becoming increasingly involuted rather than on the brink of take-off". Consistent with this view, Shiue and Keller (2007) report that the Yangtze Delta looked more like continental European countries, and was thus lagging England in terms of market integration.

Clearly, this evidence is suggestive, and more careful research is needed in this area. Calculating price variations across regions for manufactured goods would be one step in the right direction. Determining production volumes of manufactured goods and the markets in which they were traded would be another step. We know that the colonies were an important market for English manufactures and hence such an analysis would have to take these international trade flows 
into account. Given the success of our theory, these future areas of research are warranted.

\section{References}

[1] Alesina, A., Spolaore, E. and Wacziarg, R., 2000. Economic Integration and Political Disintegration, American Economic Review, 90, 1276-1296.

[2] Allen, R.C., 2000. Economic Structure and Agricultural Productivity in Europe, 1300-1800, European Review of Economic History, 3, 1-25.

[3] Allen, R.C., 2006. Agricultural Productivity and Rural Incomes in England and the Yangtze Delta, c.1620-c.1820, Oxford University, mimeo.

[4] Atack, J. and Bateman, F., 2006. Table Dd1-12 in: Historical Statistics of the United States, Earliest Times to the Present: Millennial Edition, by Carter, S.B., Gartner, S.S., Haines, M.R., Olmstead, A.L., Sutch, R. and Wright, G., eds., New York: Cambridge University Press.

[5] Atack, J., Bateman, F. and Margo., R., 2008. Steam Power, Establishment Size and Labor Productivity Growth in 19th Century American Manufacturing, Explorations in Economic History, 45, 185-198.

[6] Backus, D., Kehoe, P.J. and Kehoe, T.J., 1992. In Search of Scale Effects in Trade and Growth, Journal of Economic Theory, 58, 377-409.

[7] Barron, J.M., Umbeck, J.R. and Waddel, G.R., 2008. Consumer and Competitor Reactions: Evidence from a Field Experiment, International Journal of Industrial Organization, 26, 517531.

[8] Becker, G., Murphy, K. and Tamura, R., 1990. Human Capital, Fertility, and Economic Growth, Journal of Political Economy, 98, S12-37.

[9] Berg, M., 2002. From Imitation to Invention: Creating Commodities in Eighteenth-Century Britain, Economic History Review, LV, 1-30.

[10] Berg, M., 1994. Factories, Workshops, and Industrial Organization, in: The Economic History of Britain since 1700, R. Floud and D.N. McCloskey, eds., Cambridge: Cambridge University Press.

[11] Berman, E., Bound, J. and Griliches, Z., 1994. Changes in the Demand for Skilled Labor within U.S. Manufacturing: Evidence from the Annual Survey, Quarterly Journal of Economics, 109, 367-397.

[12] Chevalier, J., Kashyap, A.K., and Rossi, P.E., 2003. Why Don't Prices Rise During Periods of Peak Demand? Evidence from Scanner Data, American Economic Review, 93, 15-37.

[13] Chevalier, J. A. and Scharfstein, D.S., 1996. Capital-Market Imperfections and Countercyclical Markups: Theory and Evidence, American Economic Review, 86, 703-25.

[14] Clark, G., 2003. The Great Escape: The Industrial Revolution in Theory and History, UC Davis, mimeo. 
[15] Clark, G., 2002a. Farmland Rental Values and Agrarian History: England and Wales, 15001912, European Review of Economic History, 6, 281-309.

[16] Clark, G., 2002b. The Agricultural Revolution and the Industrial Revolution, UC Davis, mimeo.

[17] Cohen, W.M. and Klepper, S. 1996. Firm Size and the Nature of Innovation within Industries: the Case of Process and Product R\&D, Review of Economics and Statistics, 78, 234-243.

[18] Crafts, N.F.R., 1995. Exogenous or Endogenous Growth? The Industrial Revolution Reconsidered, Journal of Economic History, 55, 745-772.

[19] de la Croix, D. and Doepke, M. 2004. Public versus Private Education when Differential Fertility Matters, Journal of Development Economics, 73, 607-629,

[20] Desmet, K. and Parente, S.L., 2010. Bigger is Better: Market Size, Demand Elasticity and Innovation, International Economic Review, forthcoming.

[21] De Vries, J., 1993. Between Purchasing Power and the World of Goods: Understanding the Household Economy in Early Modern Europe, in: Consumption and the World of Goods, J. Brewer and R. Porter, eds., London: Routledge.

[22] Diamond, J., 1997. Guns, Germs, and Steel: The Fates of Human Societies, New York: W.W. Norton.

[23] Doepke, M. 2004. Accounting for Fertility Decline During the Transition to Growth, Journal of Economic Growth, 9, 347-383.

[24] Doepke, M. and Zilibotti, F., 2005. The Macroeconomics of Child Labor Regulation, American Economic Review, 95, 1492-1524.

[25] Ekelund, R. and Tollison, R., 1981. Mercantilism as a Rent-Seeking Society: Economic Regulation in Historical Perspective, College Station, Texas: Texas A\&M University.

[26] Ellis, C. 2006. Elasticities, Mark-ups and Technical Progress: Evidence from a State Space Approach, Working Paper 300, Bank of England.

[27] Federico, G., 2006. Feeding the World: an Economic History of Agriculture, 1800-2000, Princeton, NJ: Princeton University Press.

[28] Feinstein, C.H. and Pollard, S., 1988. Studies in Capital Formation in the United Kingdom: 1750-1920, Oxford University Press.

[29] Findlay, R. and O'Rourke, K., 2007. Power and Plenty: Trade, War and the World Economy in the Second Millennium, Princeton: Princeton University Press.

[30] Galor, O., 2009. 2008 Lawrence R. Klein Lecture - Comparative Economic Development: Insights from Unified Growth Theory, CEPR Working Paper 7519.

[31] Galor, O. and Moav, O., 2002. Natural Selection and the Origin of Economic Growth, Quarterly Journal of Economics, 117, 1133-1192. 
[32] Galor, O. and Weil, D., 2000. Population, Technology, and Growth: From the Malthusian Regime to the Demographic Transition and Beyond, American Economic Review, 90, 806-28.

[33] Gilboy, E.W. 1932. Demand as a Factor in the Industrial Revolution, in: Facts and Factors in Economic History, A.H. Cole, ed., London: Metheun.

[34] Goodfriend, M. and McDermott, J., 1995. Early Development, American Economic Review, 85, 116-33.

[35] Granovetter, M. 1984. Small is Bountiful: Labor Markets and Establishment Size, American Sociological Review, 49, 323-34.

[36] Griffiths, T., Hunt, P., and O'Brien, P., 1992. Inventive Activity in the British Textile Industry, 1700- 1800, Journal of Economic History, 52, 880-906.

[37] Hannan, T. and McDowell, J.M. 1984. The Determinants of Technology Adoption: the Case of the Banking Firm, Rand Journal of Economics, 15, 328-335.

[38] Hansen, G. and Prescott, E.C., 2002. Malthus to Solow, American Economic Review, 92, 1205-17.

[39] Harley, C.K, and Crafts, N.F.R., 2000. Simulating Two Views of the Industrial Revolution, Journal of Economic History, 60, 819-41.

[40] Hayami, Y. and Ruttan, V.W., 1971. Agricultural Development, Baltimore: The John Hopkins Press.

[41] Helpman, E. and Krugman, P.R., 1985. Market Structure and Foreign Trade, Cambridge: MIT Press.

[42] Ho, T.J., 1979. Time Costs of Child Rearing in the Rural Philippines, Population and Development Review, 5, 643-62.

[43] Hotelling, H. 1929. Stability in Competition, Economic Journal, 39, 41-57.

[44] Hummels, D. and Lugovskyy, V., 2005. Trade in Ideal Varieties: Theory and Evidence, mimeo.

[45] Jaimovich, N. and Floetotto, M., 2008. Firm Dynamics, Mark Up Variations, and the Business Cycle, mimeo, Stanford University.

[46] Jones, C.I., 1995. R\&D-Based Models of Economic Growth, Journal of Political Economy, 103, $759-84$.

[47] Jones, L.E. and Tertilt, M., 2006. An Economic History of Fertility in the U.S.: 1826-1960, NBER Working Paper \#12796.

[48] Kortum, S. 1997. Research, Patenting and Technological Change, Econometrica, 65, 1389-1419.

[49] Kremer, M. 1993. Population Growth and Technogical Change: One Million B.C. to 1990, Quarterly Journal of Economics, 108, 681-716.

[50] Lagerlöf, N.P. 2006. The Galor-Weil Model Revisited: A Quantitative Exercise, Review of Economic Dynamics 9, 116-42. 
[51] Lagerlöf, N.P. 2003. From Malthus to Modern Growth: Can Epidemics Explain the Three Regimes?, International Economic Review, 44, 755-77.

[52] Laincz, C. and Peretto, P., 2006. Scale Effects in Endogenous Growth Theory: An Error of Aggregation Not Specification, Journal of Economic Growth, 11, 263-288.

[53] Lancaster, K., 1979. Variety, Equity and Efficiency, New York: Columbia University Press.

[54] Lloyd-Jones, R., and Le Roux. A.A., 1980. The Size of Firms in the Cotton Industry: Manchester 1815-41, The Economic History Review, 33, 72-82.

[55] Lucas, R.E., 2002. Lectures on Economic Growth, Cambridge: Harvard University Press.

[56] Maddison, A. 2001. The World Economy: a Millenium Perspective, Paris: Development Centre of the OECD.

[57] Mantoux, P., 1928. The Industrial Revolution in the 18th Century, New York: Harper Torchbooks.

[58] McKendrick, N., 1982. Commercialization and the Economy, in: the Birth of a Consumer Society, N. McKendrick, J. Brewer and J.H. Plumb, eds., Bloomington: Indiana University Press.

[59] Mendels, F.F., 1972. Proto-Industrialization: The First Phase of the Industrialization Process, Journal of Economic History, 32, 241-261

[60] Mitchell, B.R., 1988. British Historical Statistics, New York: Cambridge University Press.

[61] North, D.C. and Thomas, R.P., 1973. The Rise of the Western World: A New Economic History, Cambridge: Cambridge University Press.

[62] North, D.C. and Weingast, B., 1989. The Evolution of Institutions Governing Public Choice in Seventeenth Century England, Journal of Economic History, 49, 803-32.

[63] Ottaviano, G.I.P., Tabuchi, T. and Thisse, J.-F., 2002. Agglomeration and Trade Revisited, International Economic Review, 43, 409-436.

[64] Peretto, P.F., 1998. Technological Change, Market Rivalry, and the Evolution of the Capitalist Engine of Growth, Journal of Economic Growth, 3, 53-80.

[65] Peretto, P.F., 1999. Cost Reduction, Entry, and the Interdependence of Market Structure and Economic Growth, Journal of Monetary Economics, 43, 173-195.

[66] Polanyi, K. , 1944. The Great Transformation, Boston: Beacon Press.

[67] Pollard, S., 1965. The Genesis of Modern Management, London: Penguin.

[68] Rosenzweig, M.S. and Evensen, R.E., 1977. Fertility, Schooling, and the Economic Contribution of Children in Rural India: An Econometric Analysis, Econometrica, 45, 1065-1079.

[69] Salop, S. 1979. Monopolistic Competition with Outside Goods. Bell Journal of Economics 10, 141-156. 
[70] Schultz, T. W., 1968. Economic Growth and Agriculture, New York: McGraw-Hill.

[71] Schumpeter, J. 1942. Capitalism, Socialism, and Democracy. New York, London: Harper and Brothers.

[72] Shiue, C.H. and Keller, W., 2007. Markets in China and Europe on the Eve of the Industrial Revolution, American Economic Review, 97, 1189-1216.

[73] Smith, A., 1776. An Inquiry into the Nature and Causes of the Wealth of Nations, Reprint: Oxford: Oxford University Press.

[74] Sokoloff, K.L., 1988. Inventive Activity in Early Industral America: Evidence from Patent Records, 1790-1846, Journal of Economic History, 48, 813-50.

[75] Sokoloff, K.L., 1984. Was the Transition from the Artisanal Shop to the Nonmechanized Factory Associated with Gains in Efficiency?: Evidence from the U.S. Manufacturing Censuses of 1820 and 1850, Explorations in Economic History, 21, 351-382.

[76] Stokey, N., 2001. A Quantitative Model of the British Industrial Revolution, 1780-1850, Carnegie-Rochester Conference Series on Public Policy, 55-109.

[77] Styles, J., 2000. Product Innovation in Early Modern London. Past and Present, 168, 124-169.

[78] Szostak, R., 1991. The Role of Transportation in the Industrial Revolution, Buffalo, NY: McGill-Queens University Press.

[79] Szostak, R., 1989. The Organization of Work: The Emergence of the Factory Revisited, Journal of Economic Behavior and Organization,11, 343-58.

[80] Thompson, E.P., 1963. The Making of the English Working Class, New York: Vintage Books.

[81] Toynbee, A., 1884. Toynbee's Industrial Revolution: A Reprint of Lectures on the Industrial Revolution, New York and Newton Abbot: David and Charles.

[82] Tybout, J., 2003. Plant- and Firm-level Evidence on the 'New' Trade Theories, in: E. Kwan Choi and James Harrigan, eds., Handbook of International Trade, Oxford: Basil-Blackwell.

[83] Voigtländer, N. and Voth, H.-J., 2006. Why England? Demographic Factors, Structural Change and Physical Capital Accumulation during the Industrial Revolution, Journal of Economic Growth, 319-61.

[84] Weatherhill, L.,1988. Consumer Behavior and Material Culture in Britain, 1660-1770, New York: Routledge.

[85] Williamson, J.G. 1985. The Urban Transition during the First Industrial Revolution: England, 1776-1871, mimeo.

[86] Yang, D.T. and X. Zhu, 2008. Modernization of Agriculture and Long-Term Growth, mimeo.

[87] Yang, X. and B.J. Heijdra, 1993. Monopolistic Competition and Optimum Product Diversity, American Economic Review 83, 295-301.

[88] Young, A., 1998. Growth Without Scale Effects, Journal of Political Economy, 106, 41-63. 